5105-77

Solar Thermal Power Systems Project

Research and Advanced Development
DOE/JPL-1060-42

Distribution Category UC-62e

\title{
Fracture Mechanics of Cellular Glass
}

J. G. Zwissler

M. A. Adams

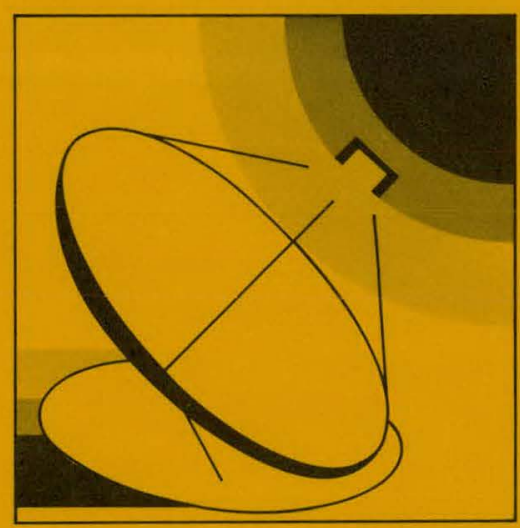

February 1, 1981

Prepared for

U.S. Department of Energy

Through an agreement with

National Aeronautics and Space Administration

by

Jet Propulsion Laboratory

California Institute of Technology

Pasadena, California

(JPL PUBLICATION 81-16) 


\section{DISCLAIMER}

This report was prepared as an account of work sponsored by an agency of the United States Government. Neither the United States Government nor any agency Thereof, nor any of their employees, makes any warranty, express or implied, or assumes any legal liability or responsibility for the accuracy, completeness, or usefulness of any information, apparatus, product, or process disclosed, or represents that its use would not infringe privately owned rights. Reference herein to any specific commercial product, process, or service by trade name, trademark, manufacturer, or otherwise does not necessarily constitute or imply its endorsement, recommendation, or favoring by the United States Government or any agency thereof. The views and opinions of authors expressed herein do not necessarily state or reflect those of the United States Government or any agency thereof. 


\section{DISCLAIMER}

Portions of this document may be illegible in electronic image products. Images are produced from the best available original document. 


\title{
Fracture Mechanics of Cellular Glass
}

\author{
J. G. Zwissler \\ M. A. Adams
}

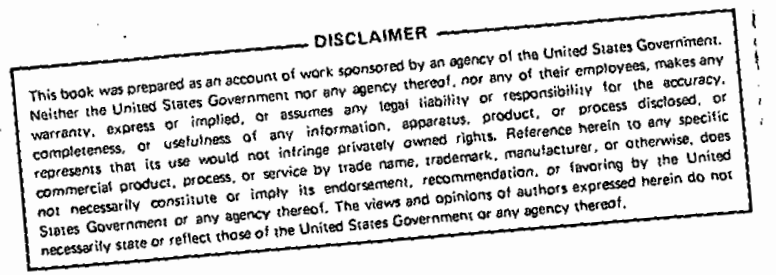

February 1, 1981

Prepared for

U.S. Department of Energy

Through an agreement with

National Aeronautics and Space Administration

by

Jet Propulsion Laboratory

California Institute of Technology

Pasadena, California

(.IPI PIIRIII.ATION 81-16) 
Prepared by the Jet Propulsion Laboratory, California Institute of Technology, for the U.S. Department of Energy through an agreement with the National Aeronautics and Space Administration.

This report was prepared as an account of work sponsored by the United States Government. Neither the United States nor the United States Department of Energy, nor any of their employees, nor any of their contractors, subcontractors, or their employees, makes any warranty, express or implied. or assumes any legal liability or responsibility for the accuracy, completeness or usefulness of ariy information, apparatus, product or process disclosed, or represents that its use would not infringe privately owned rights.

Reference herein to any specific commercial product, process, or service by trade name, trademark, manufacturer, or otherwise does not necessarily constitute or imply its endorsement, recommendations, or favoring by the United States Government or any agency thereof. The views and opinions of authors expressed herein do not necessarily state or reflect those of the United States Government or any agency thereof. 


\section{ACKNOWLEDGMENT}

The authors gratefully acknowledge the contributions of $T$. Arge who supervised the mechanical testing and data reduction for this program and the contribution of $\mathrm{T}$. Hill who conducted the mechanical testing. The authors extend thanks to $S$. Myers for typing the manuscript.

This work was performed in support of the Jet Propulsion Laboratory/ Solar Thermal Power Systems Project/Research and Advanced Development Materials Program. The work was performed by the Materials Research and Technology Group of the Applied Mechanics Division of the Jet Propulsion Laboratory, California Institute of Technology. 


\section{ABSTRACT}

Cellular glasses are prime candidate materials for the structural substrate of mirrored glass for solar concentrator reflecting panels. These materials possess properties desirable for this application such as high stiffness to weight ratio, dimensional stability, projected low cost in mass production and, importantly, a close match in thermal expansion coefficient with that of the mirror glass. These materials are brittle, however, and susceptible to mechanical failure from slow crack growth caused by a stress corrosion mechanism.

This report details the results of one part of a program established to develop improved cellular glasses and to characterize the behavior of these and commercially available materials. Commercial and developmental cellular glasses were tested and analyzed using standard testing techniques and models developed from linear fracture mechanics. Two models describing the fracture behavior of these.materials are developed. Slow crack growth behavior in cellular glass was found to be more complex than that encountered in dense glasses or ceramics. I'he crack velocity was found to be strongly dependent upon water vapor transport to the tip of the moving crack. The existence of a static fatigue limit was not conclusively established, however, it is speculated that slow crack growth behavior in Region I may be slower, by orders of magnitude, than that found in dense glasses. 
CONTENTS

I. INTRODUCTION ......................... . . 1-1

II. THEORETICAL ANALYSIS . . . . . . . . . . . . . . . . 2-1

III. EXPERIMENTAL PROCEDURE . . . . . . . . . . . . . . . . . . 3-1 A. $\mathrm{K}_{\mathrm{IC}}, \mathrm{G}_{\mathrm{IC}}$ Determination . . . . . . . . . . . . . 3-1 B. DOUBLE TORSION TESTING . . . . . . . . . . . . . . 3-4

IV. RESULTS AND DISCUSSION . . . . . . . . . . . . . . . . 4-1

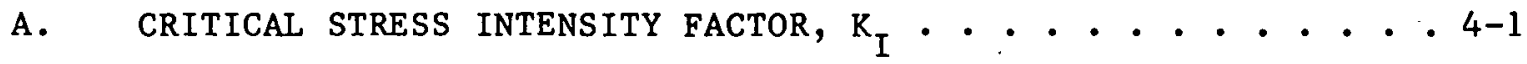

B. DOUBLE TORSION: $\mathrm{v}$ vs. $\left(\mathrm{K}_{\mathrm{I}} / \mathrm{K}_{\mathrm{IC}}\right) \cdot \cdot \cdot \cdot \cdot \cdot \cdot \cdot \cdot \cdot \cdot \cdot \cdot 4-3$

C. CRITICAL STRAIN ENERGY RELEASE RATE, $\mathrm{G}_{\mathrm{IC}} \cdot \cdot \cdot \cdot \cdot \cdot \cdot \cdot \cdot$. $\cdot$ - 18

D. CRITICAL FlAW SIZE DISTRIBUTION, $c_{c} \cdot \cdot \cdot \cdot \cdot \cdot \cdot \cdot \cdot \cdot$.

V. SUMMARY . . . . . . . . . . . . . . . . . . . 5-1

VI. CONCLUSIONS . . . . . . . . . . . . . . . . . . 6-1

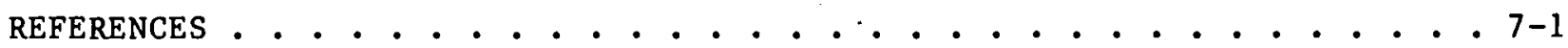

APPENDIX

A. A MOdEL FOR THE MEChanical Behavior OF FOAMGlas ${ }^{\circledR}$. . . . . . . . . A-1

A.1. DEFINITIONS . . . . . . . . . . . . . . . . . A-1

A.2. Cellular GlasS MOdEL . . . . . . . . . . . . . . . . . A-2

\section{$\underline{\text { Figures }}$}

1. Cellular Glass Models: Bulk and Microscopic . . . . . . 2-2

2. The Variation of Crack Velocity as a Function of Stress Intensity Factur for a Material Subjected to a Stress

Corrosion Environment ............. 2-5

3. The Single-Edge Notched Beam (SENB) Specimen Configuration . 3-3 
4. The Double Torsion Specimen ............. 3-5

5. Cellular Glass Fracture Toughness as a Function of Density . 4-2

6. Foamglas ${ }^{\circledR}$ Double Torsion Compliance Calibration Curve . . . 4-4

7. Foamglas ${ }^{\circledR}$ Fast Fracture Strength Weihull Analysis . . . . 4-6

8. Foamglas ${ }^{\circledR}$ Weibul1 Probability of Failure vs. the Static

Fatigue Stress Limit . . . . . . . . . . . . . . 4-7

9. Crack Velocity vs. Stress Intensity Factor for Foamglas ${ }^{\circledR}$

Specimen 1... . . . . . . . . . . . . . . . 4-9

10. Crack Velocity vs. Stress Intensity Factor for Foamglas ${ }^{\circledR}$

Spccimen 2......................4 10

11. The Stress Corrosion Exponent Intervals Determined From the Curves of Figures 9-10 for Various Confidence Levels . . . . 4-11

12. The Stress Corrosion Coefficients Intervals Determined From the Curves of Figures 9-10 for Various Confidence Levels . . 4-12

13. Schematic of Water Transport to the Crack Tip in Cellular Glass ....................... . 4-14

14. A Comparison of the Slow Crack Growth Behavior for Cellular Glasses in Relation to that of Dense Glasses . . . . . . . 4-16

15. The Critical Flaw Size Distribution in Foamglas $₫$ tor Various Flaw Mode1s: Case 1, a Penny-shaped Flaw on the Surface of the Specimen; Case 2, a Through Notch Across the Specimen Surface; Case 3, a Through Crack in Cell Glass Wall , . . 4-20

A-1. The "Egg Crate" Model for Cellular Glass . . . . . . . . . A-3

\section{Tables}

1. Nominal Oxide Composition, Density and Number of Test Specimens of the Cellular Glass . . . . . . . . . . . 3-2 


\section{SECTION I}

\section{INTRODUCTION}

Cellular glasses have a long history as self-supporting insulation materials for both hot and cold applications. Therefore, optimizing their thermal insulating properties has been emphasized in developing these materials. Consequently, little interest was shown in the mechanical behavior of the cellular glasses because of the minimal structural requirements in this traditional application.

Recent interest in achieving highly accurate reflective mirror systems for solar thermal energy conversion programs has resulted in the search for a durable, low-cost and light-weight structural substrate for mirror glass reflectors. Cellular glasses have been identified as a prime candidate for these optical, structural substrates due to their low density, close thermal expansion match to the mirror glass, and projected low cost. This novel application for these materials demands much greater structural integrity than the traditional insulation applications. An initial study was performed by . JPL to assess the suitability of using this material in a mirror panel application (Reference 1). Subsequently, additional in-depth studies were carried out to gather basic design data and answer specific questions concerning the use of these materials in solar thermal systems. This report deals with the fracture mechanics investigations which include measurement of the critical stress intensity factor $\left(K_{I C}\right)$ for various cellular glasses and determination of the crack velocity vs. stress intensity factor relationship for Heavy Load Bearing (HLB) Foamglas $\left.{ }^{(}\right)$(trade name of the Pittsburgh Corning Corporation, Pittsburgh, PA.). Fast fracture strength determinations for this same material are also reported. 
Description of the stress intensity factor for dense, homogeneous, isotropic solids which exhibit linear elastic behavior can readily be described by the well-known relationship (Reference 2):

$$
\mathrm{K}_{\mathrm{I}}=\sigma_{\mathrm{A}} \mathrm{Y} \sqrt{\mathrm{C}}
$$

Where $K_{I}$ is the stress intensity factor for opening mode $I, \sigma_{A}$ is the stress applied to the material at some distance remote from the crack tip, $\mathrm{Y}$ is a dimensionless parameter which depends upon the geometry of the loading and crack configuration and $C$ is the characteristic dimension of the flaw. In loading a material, once $\mathrm{K}_{\mathrm{I}}$ reaches a critical value denoted $\mathrm{K}_{\mathrm{IC}}$, unstable crack growth occurs. $\mathrm{K}_{\mathrm{IC}}$ is typically considered to be an intrinsic material property which may be used to characterize the material's mechanical integrity.

Cellular glasses are foamed, inorganic glasses (See Ref. 1 for a. description of the manufacturing process). As such they are microscopically porous, heterogeneous materials on the scale of millimeters (Figure 1). In highly porous materials such as polymeric foams or inorganic glass foams, the physical interpretation of the terms in Equation I becomes uncertain. In such materials a microscopic structure exists which may profoundly influence the nature or interpretation of the variables in Equation 1. (The properties reported in this paper are bulk values.) The appropriate fracture mechanics modcl for cellular glasses which contain high volume fractions of pores (75-95 vol\% porosity) may be one of modelling both the microscopic stresses in the cell walls and the nature of the cracks in these cell walls vis-a-vis modelling the cracks as though they existed in a continuous medium. This would be done with particular bulk elastic constants and nominal stress levels derived from the bulk elastic constants (see Figure 1).

Figure la illustrates the bulk model for cellular glasses. This model considers the material as a composite material composed of two phases, one 


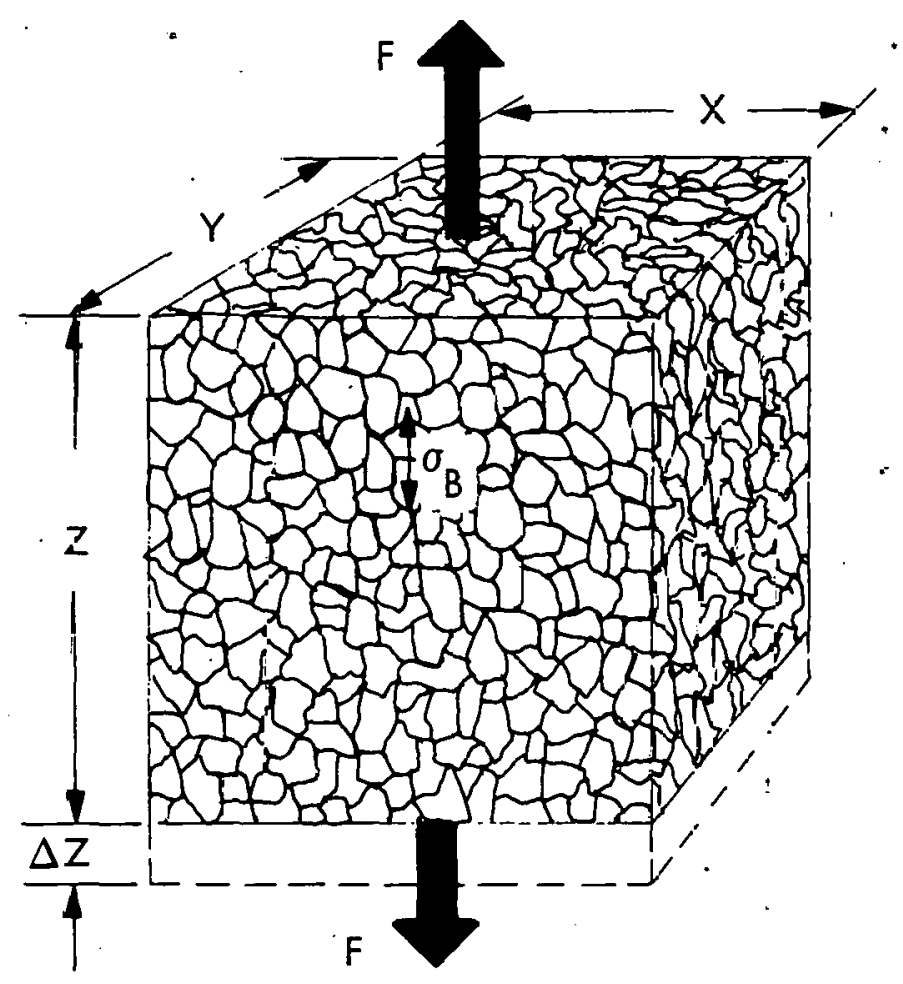

(a) BULK MODEL

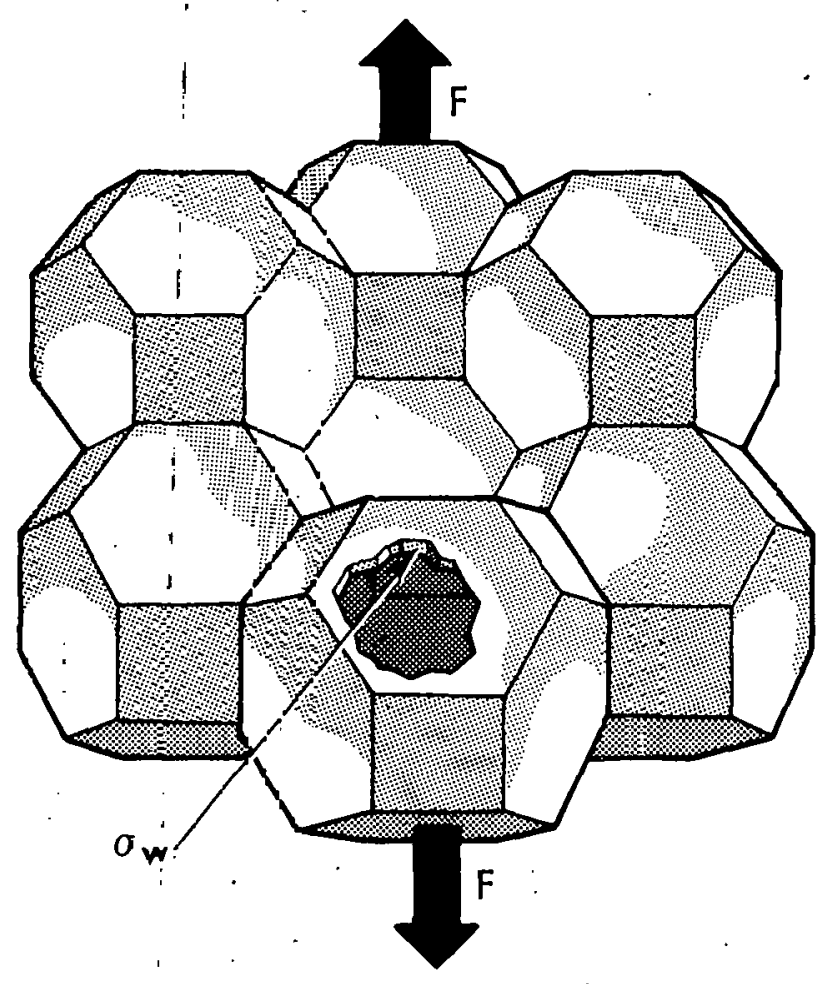

(b) MICROSCOPIC MODEL

Figure 1. Cellilar Elaiss Models: Bulk and Microscopic 
being dense glass and the other the gas in the closed pores. This model suggests use of the law of mixtures to predict the mechanical properties. The pore gas occupies a specific fraction of the bulk volume but does not possess any mechanical strength or tensile elastic modulus. The bulk stress in this model is determined by dividing the applied load by the cross-sectional area over which the load is applied, as measured from the bulk dimensions of the specimen. The bulk elastic modulus is then the bulk stress divided by the bulk strain. The various fracture mechanics parameters are then determined from these bulk stresses and bulk elastic constants.

The microscopic model of cellular glasses is illustrated in Figure $1 \mathrm{~b}$. In this model the material is considered as a continuous, three dimensional structure composed of thin, doubly-curved, dense glass cell walls. In this mode 1 the stresses in the cell walls are determined by dividing the load applied to the body by the load carrying cross-sectional area of the cell walls. The strain in the cell walls is the ratio of the stress in the cell walls to the modulus of the dense glass in these walls. In this microscopic model, rotations of the cell wall structure, which produce bulk displacement under load, may occur without generating appreciable stresses in the cell walls. If such flexing of the cell walls does occur, this would lead to larger bulk displacements than would be predicted by the microscopic model and one would expect deviations from elastic constants predicted by the law of mixtures. These deviations would cause the measured modulus to be less than that predicted by either model, especially at lower densities.

Cellular glasses are susceptible to the phenomenon of subcritical crack excension (References 1 and 3). As determined for dense glass, this is believed to be stress corrosion phenomenon, the primary corrosive medium being water vapor present in the environment (References 4 and 5). In this physical process, when the material is subjected to a stress below its ultimate strength, the flaws inherent within the material grow as a function of time. The rate of growth of these subcritical flaws (i.e. the crack velocity $V$ ) is a function of the stress intensity factor $K_{I}$ : Experimental data on many brittle ceramic materials have been adequately described by the following empirical relationship:

$$
\mathrm{V}=\mathrm{AK}_{\mathbf{I}}{ }^{\mathrm{n}}
$$


This form of the equation describing the $V, K_{I}$ relationship suffers from the complication that the dimensions of $\mathrm{A}$ are dependent upon the stress corrosion exponent $n$ and the expression does not contain the fundamental property of the material, $\mathrm{K}_{\mathrm{IC}}$. A simple comparison of A values for materials with different stress corrosion exponents is not possible since the physical basis of the parameters $A$ and $n$ have not been established and their behavior has been observed to be coupled in experimental data. Likewise, a comparison of only $n$ values between materials is not conclusive. Minnear and Bradt (Reference 6) and Sines (Reference 7) have suggested a more useful form of this relationship given by the following equation:

$$
\mathrm{V}=\beta\left(\mathrm{k}_{\mathrm{I}} / \mathrm{K}_{\mathrm{IC}}\right)^{\mathrm{n}}
$$

In this case $K_{I}$ is normalized to the $K_{I C}$ value for the material and $\beta$ now has the dimensions of velocity for all materials, which greatly facilitates comparison of $\beta$ and $n$ values for different materials.

The idealized relationship of equation ( 3 ) is illustrated in Figure 2 which is plotted on a $\log v$ s. $\log$ scale. Figure 2 indicales a minimum required value of $k_{I}$ for stress corrosion to occur, i.e., a stress corrosion limit below which no subcritical crack growth will occur. Above this threshold value, $\mathrm{K}_{\mathrm{o}}$, the behavior has been modeled (References 8 and 9) as exhibiting three regions of crack growth for dense glass and ceramics. In region $I$, at low values of $\mathrm{K}_{I}$, the rate of stress assisted chemical attack at the crack tip controls crack propagation. As this reaction is stress assisted, increasing the stress at the crack tip causes an increase in crack gruwth velocity. Equation (1) illustrates that this process is autocatalytic under constant or increasing loading conditions in that any crack growth (increase in $C$ ) results in an increase in stress intensity at the crack tip thereby causing an increase in crack velocity. As the combination of increased crack length and/or increased stress causes an increase in $K_{I}$, the crack velocity increases in Reginn $I$, as shown by the curve, until $K_{T}$ attains the value at which the onset of region II crack growth behavior occurs. In region II the process is believed to be controlled by the rate of diffusion of water vapor to the crack tip and crack velocity is found to be nearly independent of stress intensity. 


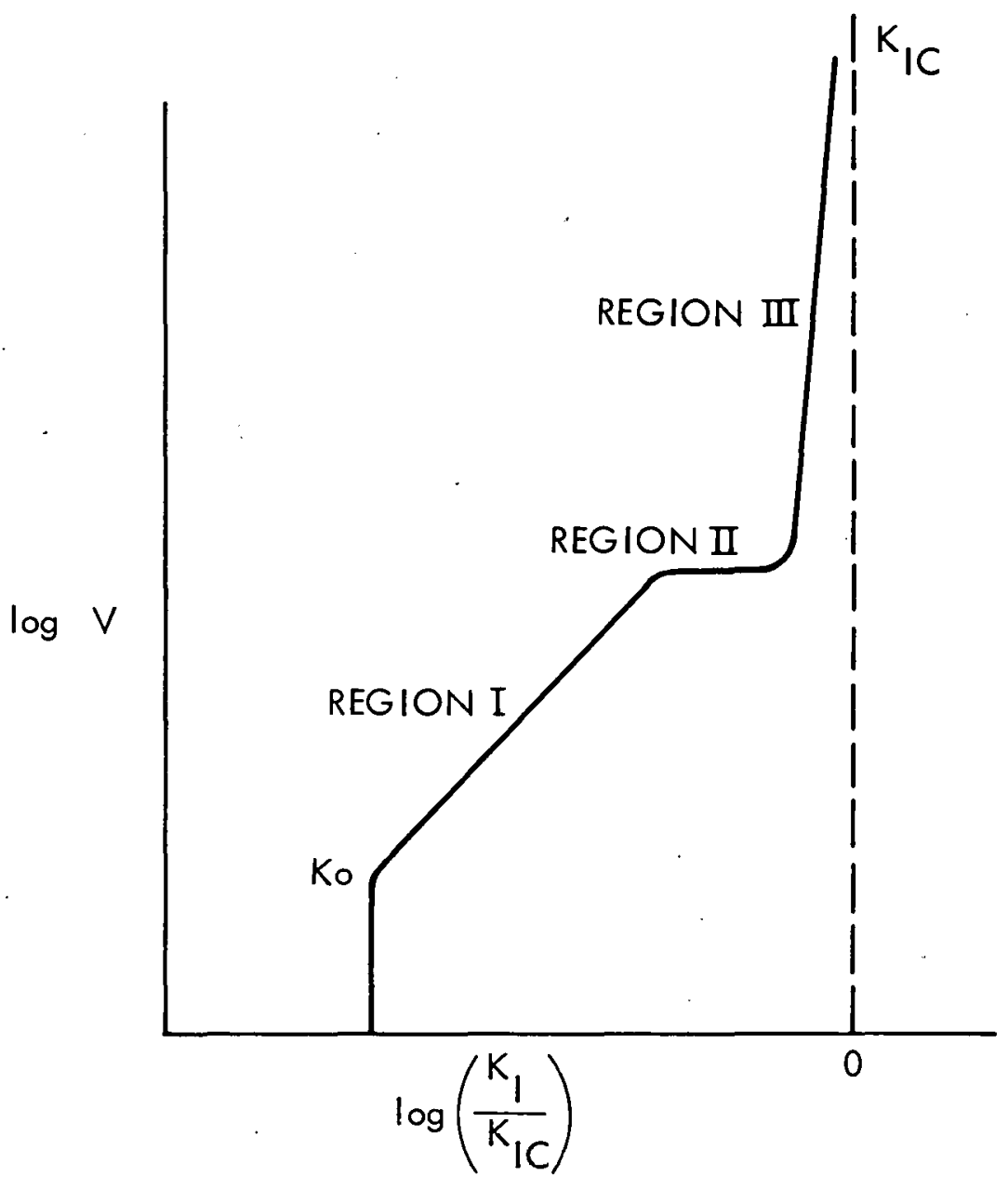

Figure 2. The Variation of Crack Velocity as a Function of Stress Intensity Factor for a Material Subjected to a Stress Corrosion Environment 
In region $I I I, K_{I}$ is close to $K_{I C}$ and the process can be described as consisting of thermally activated bond cleavage and again the crack velocity becomes very sharply dependent upon the stress intensity factor.

For most engineering applications, the crack velocities of regions II and III are sufficiently rapid as to cause immediate failure of any component loaded to these $K_{I}$ levels. Region I behavior is, therefore, the region of interest for design purposes. There is controversy as to whether the threshold $K_{0}$ does, indeed, exist or whether crack velocities continue to be finite at lower $\mathrm{K}_{I}$ 's but are merely of such a small magnitude as to be extremely difficult to measure in the short time period available for experiments (Reference 10 ), i.e., $10^{-10} \mathrm{~m} / \mathrm{sec}$. In dense glasses, $\mathrm{K}_{0}$ has been determined by some investigators (References 11-14) to be on the order of $20 \%$ to $40 \%$ of the $\mathrm{K}_{\mathrm{IC}}$ value for the material, that is, with very small decreases in $\mathrm{K}_{\mathrm{I}}$, the crack velocity became negligibly small and was assumed to have a negligible effect on design lifetime. It is of engineering interest, therefore, to determine the static fatigue limit for the cellular glass material, since, at stress levels corresponding to $\mathrm{K}_{\mathrm{I}}<\mathrm{K}_{\mathrm{o}}$ i.e. $\sigma<\sigma_{0}$, designs are possible in which the static fatigue phenomena may be ignored in predicting reliability. This is a considerable simplification in the prediction of performance.

This investigation attempted to determine both $\mathrm{K}_{0}$ and $\mathrm{K}_{\mathrm{IC}}$ for HLB Foamglas ${ }^{\circledR}$, a soda-1ime silicate cellular glass. Fast fracture behavior and slow crack growth behavior of the $\mathrm{V}$ v.s. $\mathrm{K}_{\mathrm{I}}$ diagram depicted in Figure 2 were also investigated. Two other developmental cellular glasses were investigated to determine $K_{I C}$ only. 
A. $\mathrm{K}_{\mathrm{IC}}, \mathrm{G}_{\mathrm{IC}}$ DETERMINATION

The critical stress intensity factor for opening mode, $\mathrm{K}_{\mathrm{IC}}$, was determined for one commercial and two developmental cellular glass materials. The materials are listed in Table I which identifies the nominal chemistry, density and number of specimens available for testing. Single-edge notched beam (SENB) specimens, illustrated in Figure 3, were machined from large blocks of cellular glass received from the material suppliers. Each beam was weighed and dimensionally characterized for density determination and subsequent input to fracture mechanics equations. The beams were loaded to failure in uniform bending on a screw-type Instron Testing Machine (Model 1122, Instron Corporation, Canton, Mass.). Four-point line loading was applied using 2.5-cm diameter cylinders. The specimen dimensions were chosen to preclude surface crushing of the cellular glass under the loading cylinders.

The beams were loaded rapidly in an attempt to minimize the effect of slow crack growth during the loading interval. The Instron crosshead was set to run at $51 \mathrm{~cm} / \mathrm{min}$. Under this loading condition the interval of the fracture event from the initial load application to failure was on the order of 50 milliseconds. Special instrumentation was required for accurate data acquisition due to the relatively slow response of the Instron chart recorder at these rapid loading rates. The signals from the load cell and from a linearly variable differential transducer used to measure crosshead motion, were input to a fast-response 1 ight-pen recorder (Honeywel1 Oscillographic Recorder, Visicorder Model 1858) set to run at $25 \mathrm{~cm} / \mathrm{sec}$. With this instrumentation the load data could be accurately acquired during the short time interval of the fracture event with a resolution of fractions of a millisecond. The critical stress intensity factor values were determined from the following equation (Reference 15): 
Table 1. Nominal Oxide Composition, Density and Number of Test Specimens of the Cellular Glass

Foamglas ${ }^{\mathbb{R}_{*}} \quad \begin{gathered}\text { Experimenta1** } \\ \text { Aluminoborosilicate } \\ \text { Cellular Glass }\end{gathered}$

Foamsil@ $75 *$

$\mathrm{SiO}_{2}$

72

69

67

$\mathrm{Al}_{2} \mathrm{O}_{3}$

5

11

10

$\mathrm{B}_{2} \mathrm{O}_{3}$

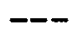

4

4

$\mathrm{H}_{2} \mathrm{O}$

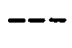

5

5

$\mathrm{Fe}_{2} \mathrm{O}_{3}$

3

3

Alkali Oxides

$\left(\mathrm{R}_{2} \mathrm{O}\right)$

13

8

Alkaline Earth

Oxides (RO)

10

Nominal Density

$\mathrm{Kg} \mathrm{\textrm {m } ^ { - 3 }}$

136

320

192

Number of Specimens

23

13

52

* Trade name of Pittsburgh Corning Corporation, Pittsburgh, PA

**Developmental material supplied by Pittsburgh Corning Corporation,

Pittsburgh, PA. Coefficient of thermal expansion of $70 \times 10^{-7} /{ }^{\circ} \mathrm{C}$.

$$
\left.K_{I C}=\frac{3 P_{c} l}{b W^{2}} C^{1 / 2} \mid 1.99-2.47\left(\frac{C}{W}\right)+12.97\left(\frac{C}{W}\right)^{2}-23.17\left(\frac{C}{W}\right)^{3}+24.8\left(\frac{C}{W}\right)^{4}\right\}
$$

where $P_{c}$ is the critical applied load, $l$ is the four point loading moment arm length, $b$ and $W$ are specimen thickness and height respectively and $c$ is the notch depth. $G_{I C}$, the critical strain energy release rate can be calculated from the following relationship for plane strain conditions:

$$
G_{I C}=\frac{K^{2} I C\left(1-\nu^{2}\right)}{E}
$$



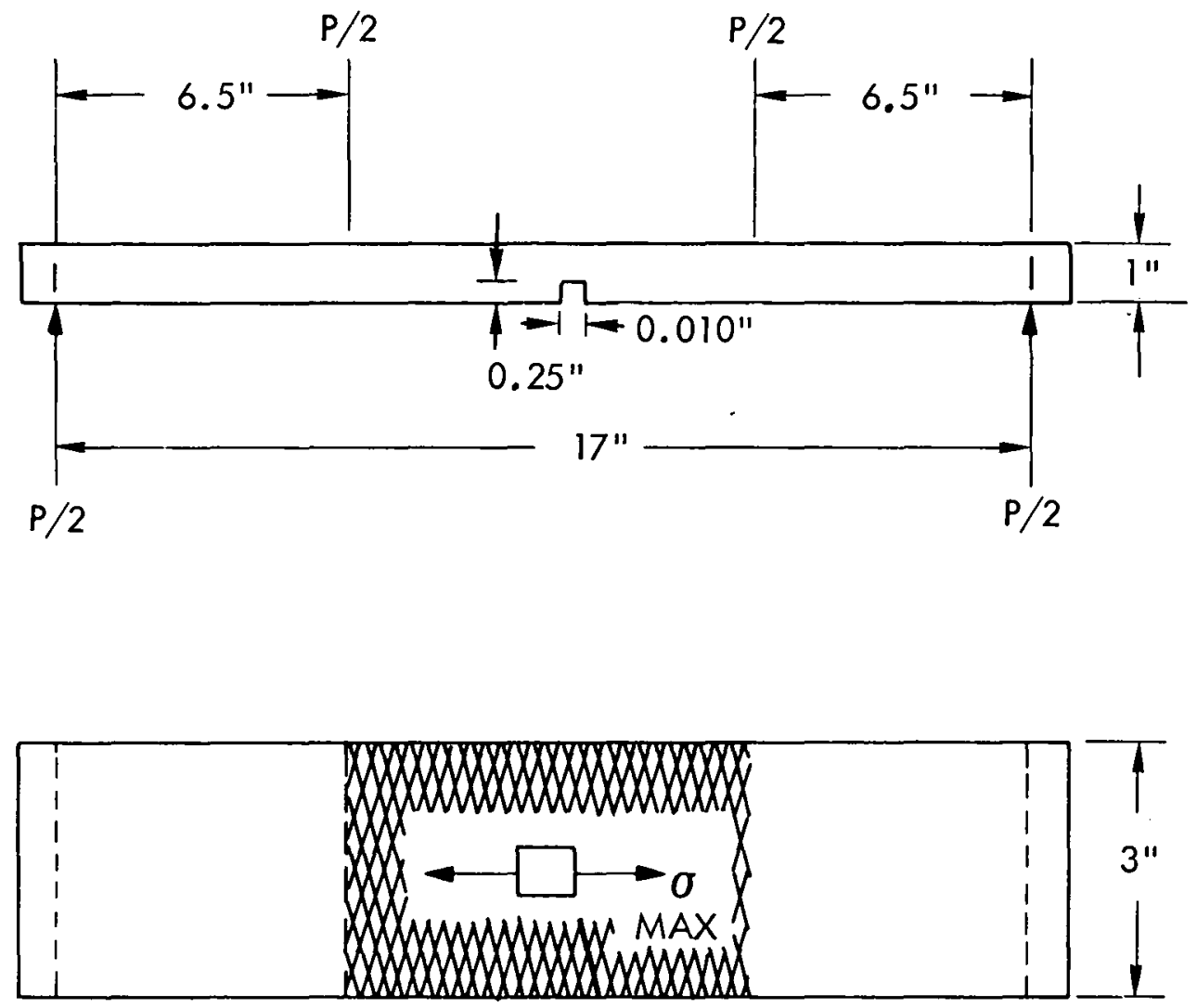

\section{STRESS \\ ON \\ BOTTOM \\ FIBERS}

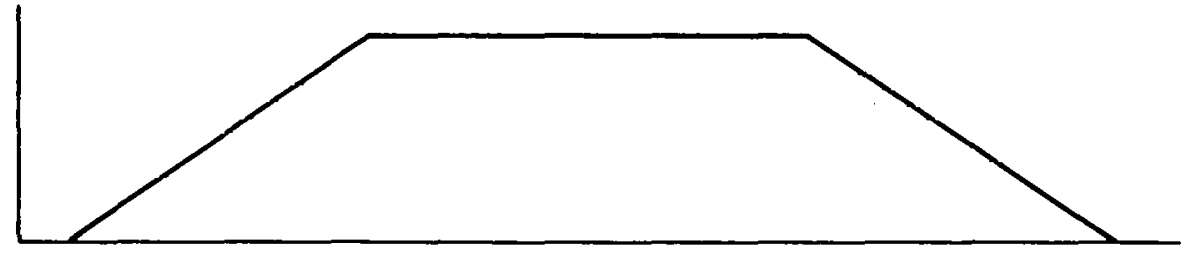

LOCATION

Figure 3. The Single-Edge Notched Beam (SENB) Specimen Configuration 
where $\mathrm{E}$ is the Young's modulus and $\nu$ is Poisson's ratio. The $\left(1-\nu^{2}\right)$ term is eliminated for conditions of plane stress. The difference between the two conditions is negligible due to the small magnitude of Poisson's ratio.

Analysis of the dynamics effects during specimen loading and experimental verification of these conditions indicated that these dynamic effects contributed less than $1 \%$ error in the worst case test. Acceleration forces on the top loading fixture and specimen were minimized by reducing the weight of the top fixture. The natural frequency of the fixturing and specimen was much greater than that required to strongly interact with the load application.

\section{B. DOUBLE TORSION TESTING}

A detailed analysis of the double torsion test technique may be found in the literature (References 9 and 16-22). Figure 4 illustrates the double torsion specimen as well as a definition of the various geometrical parameters and the four point loading configuration. The cell size of the cellular glass was on the order of 1-2 m. Specimen sizes much larger than those reported in the literature as being useful for investigating dense glass and struclural ceramics were utilized in this investigation in an attempt to achieve a representative microstructure in the test section. Two specimen configurations were used. The testing of thick section specimens was accomplished usiug the following typical dimensions: $L=46 \mathrm{~cm}, W=30 \mathrm{~cm}, W_{m}=13 \mathrm{~cm}, \mathrm{~d}=5 \mathrm{~cm}$ and $\mathrm{dw}=3.8 \mathrm{~cm}$. It was found that to achieve an accurate compliance calibration a thinner section specimen configuration was required. In this configuration, $L, W$ and $W_{m}$ remained the same while $d=1.9 \mathrm{~cm}$ and $d_{W}=1.3 \mathrm{~cm}$.

An elastic analysis of the torsional plate loading leads to the following relationship (see Reference 16):

$$
K_{I}=P W_{m}\left\{\frac{3(1+\nu)}{W d^{3} d_{w}}\right\}^{1 / 2}
$$




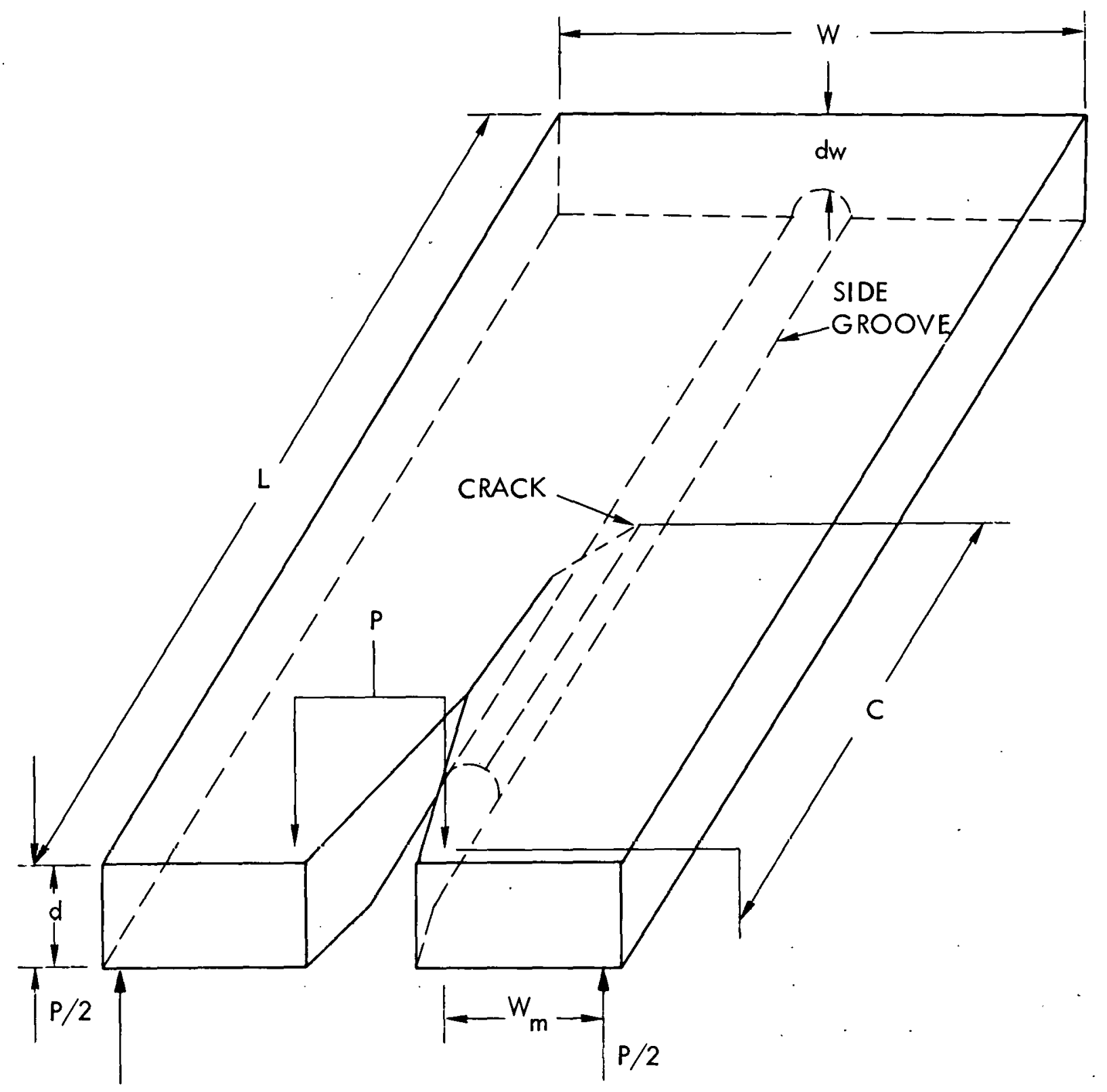

Figure 4. The Double Torsion Specimen 
where $\nu=$ Poisson's ratio and the other parameters are defined in Figure 4. Further analysis (Reference 20) has indicated that a correction factor $\psi(t)$ must be introduced due to the finite thickness of the double torsion specimens. The parameter $t$, the thinness ratio, is equal to $2 d / w$. The corrected equation then becomes:

$$
\mathrm{K}_{I}=P W_{m}\left\{\frac{3(1+\nu)}{W d^{3} d_{w} \psi(t)}\right\}^{1 / 2}
$$

Where $\psi(t)=0.9212$ for the thin section specimens used in this investigation. Equations 6 and $6 \mathrm{a}$ imply that $\mathrm{K}_{\mathrm{I}}$ is independent of crack length for this specimen configuration. Recent work (Reference 22) indicates that a constant $\mathrm{K}_{\mathrm{I}}$, independent of crack length, is obtained only when the crack is propagating in the central portion of the specimen i.e., end effects become important for relatively short or long cracks so care must be taken to achieve data free from these effects.

The double torsion specimen may be tested in various modes to obtain the fracture mechanics data required for characterizing the subcrilical crack growth behavior of a material. One mode utilized in this investigation was the load relaxation technique. If it can be demonstrated in a compliance calibration that the displacement, $y$, is linearly related to the crack length $C$ and load P:

$$
y=P\left(B C+\lambda_{0}\right)
$$

where $B$ and $\lambda_{0}$ are constants determined from the compliance calibration that depend 'upon the elastic modulus of the material and the dimensions of the material and test device, then it can be shown that the crack velocity is related to the instantaneous values of the load and the load relaxation rate under fixed grip (constant displacement) mode of testing according to the following relation (see Reference 16):

$$
\mathrm{V}=-\frac{\mathrm{P} i, \mathrm{f} \dot{\mathrm{P}}}{\mathrm{P}^{2}}\left(\mathrm{ci}, \mathrm{f}+\frac{\lambda_{\mathrm{o}}}{\mathrm{B}}\right)
$$


where the subscripts " $i$ " and " $f$ " refer respectively to the initial or final values of $P$ and $C$ for the test run. $P$ and $\dot{P}$ are the instantaneous values of the load and the load relaxation rate respectively. The specimen is loaded rapidly to $\mathrm{Pi}$ where the machine crosshead is fixed. The crack begins to propagate rapidly but decelerates as the load relaxes according to equation (8). When the load relaxation rate decreases to zero the crack velocity is zero. In this test, one obtains data points at decreasing values of $\left(\mathrm{K}_{\mathrm{I}} / \mathrm{K}_{\mathrm{IC}}\right)$ on the $\mathrm{V}$ vs. $\left(\mathrm{K}_{\mathrm{I}} / \mathrm{K}_{\mathrm{IC}}\right)$ curve of Figure 2 and approaches $\mathrm{K}_{\mathrm{O}}$ conditions i.e., $V=0$, at long times. For the specimen configuration utilized in this investigation up to three load relaxation runs could be made on a single specimen to generate the plot in Figure 2. Once the load relaxation tests had been completed, the specimen was loaded rapidly to failure to determine $P_{c}$, the critical load from which $K_{I C}$ could be determined from equation ( $6 a)$. 
A. CRITICAL STRESS INTENSITY FACTOR, $\mathrm{K}_{\text {IC }}$

The results of the single-edge notched beam tests are presented in Figure 5. The $\mathrm{K}_{\mathrm{IC}}$ data illustrate two standard deviations about the mean values of $\mathrm{K}_{\mathrm{IC}}$ and density as well as the number of beams tested for each of the three cellular glass sample populations tested. The solid curve is a least squares regression fit through the combined 96 individual $\left(P, \mathrm{~K}_{\mathrm{IC}}\right)$ data points. The correlation coefficient for the linear fit is 0.981 which indicates an excellent fit to the data.

The curve illustrates a definite 1 inear dependence of measured bulk $\mathrm{K}_{\mathrm{IC}}$ upon the specimen density over the limited range of densities investigated in this study. The material characterized in this program lies at the extreme low end of the density range; all densities being less than 15\% that of dense glass. It is of interest to note however, that extrapolation of the curve in Figure 5 (see inset Figure 5) to the density of dense $\mathrm{glass}\left(2.55 \mathrm{gm} \mathrm{cm}^{-3}\right.$ ) results in a $\mathrm{K}_{\mathrm{IC}}$ value of $0.88 \mathrm{MNm}^{-3 / 2}$. This is well within the range of values presented by Wiederhorn (Reference 23) for $\mathrm{K}_{\mathrm{IC}}$ of dense glasses measured in nitrogen gas at $300^{\circ} \mathrm{K}$. These values ranged from $0: 749 \pm 0.011 \mathrm{MNm}^{-3 / 2}$ for soda-lime glass to $0.913 \pm .022 \mathrm{MNm}^{-3 / 2}$ for aluminosilicate glass. The macroscopic fracture toughness (bulk $\mathrm{K}_{\mathrm{IC}}$ ) appears to be linearly dependent upon density for cellular glasses in the range of densities studied. The $\overline{\mathrm{K}}_{\mathrm{IC}}$ dependence on density may be related to the $\mathrm{K}_{\mathrm{IC}}$ for dense glass by the following law of mixtures relationship between the two phases, dense glass and pore gas:

$$
\mathrm{K}_{\mathrm{IC}}\left(\text { cellular glass) }=\frac{\rho_{\mathrm{CG}}}{\rho_{\mathrm{DG}}} \mathrm{K}_{\mathrm{IC}}\right. \text { (dense glass) }
$$




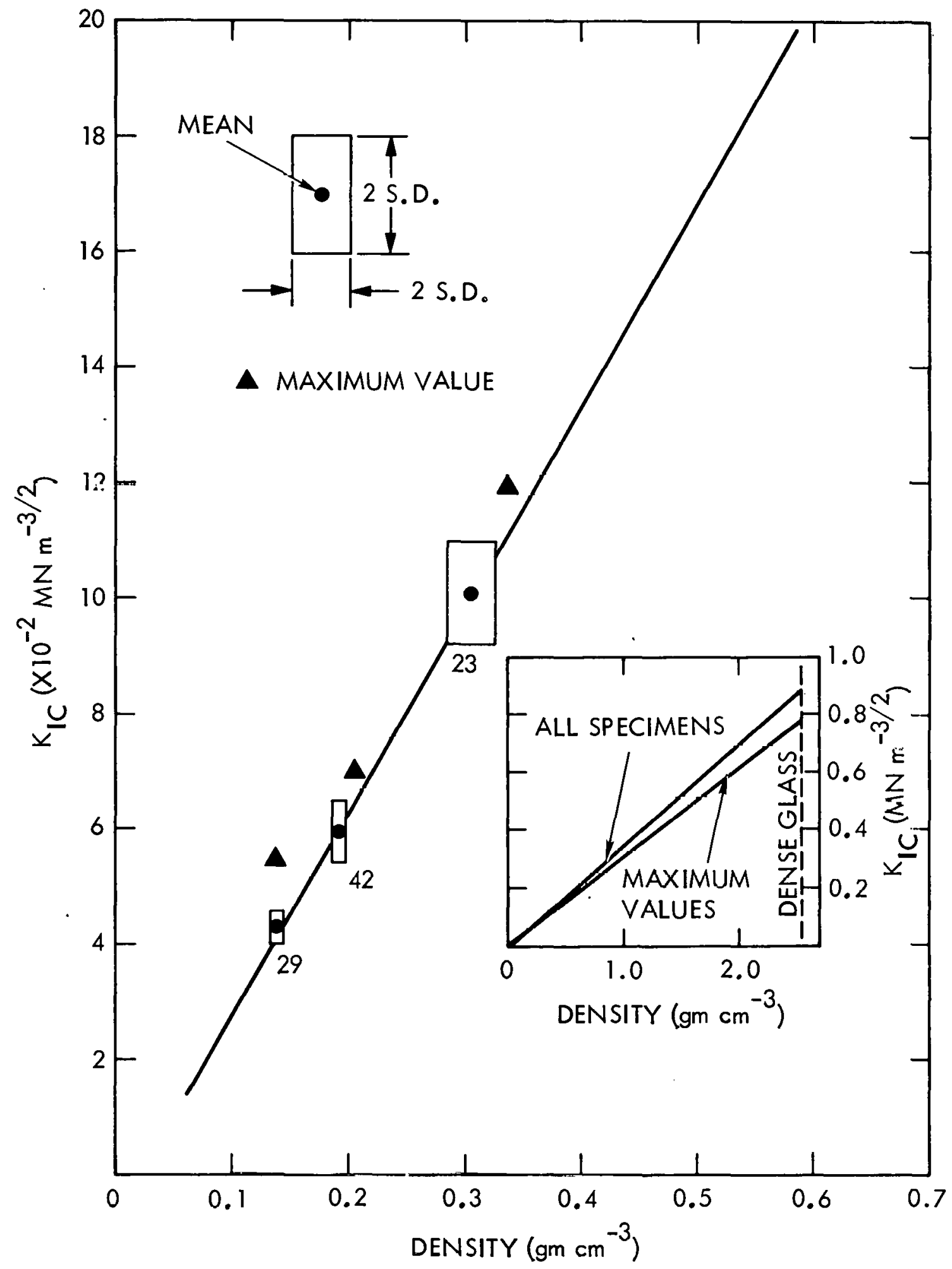

Figure 5. Cellular Glass Fracture Toughness as a Function of Density 
B. DOUBLE TORSION: V vs. $\left(\mathrm{K}_{\mathrm{I}} / \mathrm{K}_{\mathrm{IC}}\right)$

Figure 6 is the compliance calibration curve for the double torsion specimen. A point of special interest is that for dense glass and conventional ceramics $\lambda_{0} \ll B$ so the $\lambda_{0} / B$ term in equation ( 8 ) becomes negligibly small. This is not the case for cellular glass of the specimen dimensions investigated in this study which were limited by the material supplied. $\lambda_{o} / B$ was determined to be $16.0 \mathrm{~cm}$ which is the same order of magnitude as $C_{i}, f$ and therefore could not be neglected in the analysis. The slope of the compliance curve $B$, is related to the shear modulus $\mu$ by the following relation (see Reference 20):

$$
B=\frac{3 W_{m}}{\mu W d^{3} \psi(t)}
$$

From this equation $\mu$ was calculated to be $4.43 \times 10^{8} \mathrm{Nm}^{-2}\left(6.43 \times 10^{4} \mathrm{psi}\right)$. Under the assumption of linear elastic behavior, which appears valid in this case, Poisson's ratio $\nu$, was calculated to be 0.17 from the following equation:

$$
\nu=\frac{E-2 \mu}{2 \mu}
$$

Where $\mathrm{E}$ is the sonically determined elastic modulus reported by the manufacturer to be $1.0 \times 10^{9} \mathrm{Nm}^{-2}\left(1.5 \times 10^{5} \mathrm{psi}\right)$.

In the analysis of the double torsion data the normalized values of $K_{I}$ are of interest. From equation (6a):

$$
\frac{\mathrm{K}_{I}}{\mathrm{~K}_{I C}}=\frac{\mathrm{P}}{\mathrm{P}_{C}}
$$

where $K_{I}$ is the stress intensity factor at any load $P . P_{C}$ is the critical load attained upon rapid loading to failure after completion of the load 
CRACK LENGTH (in.)

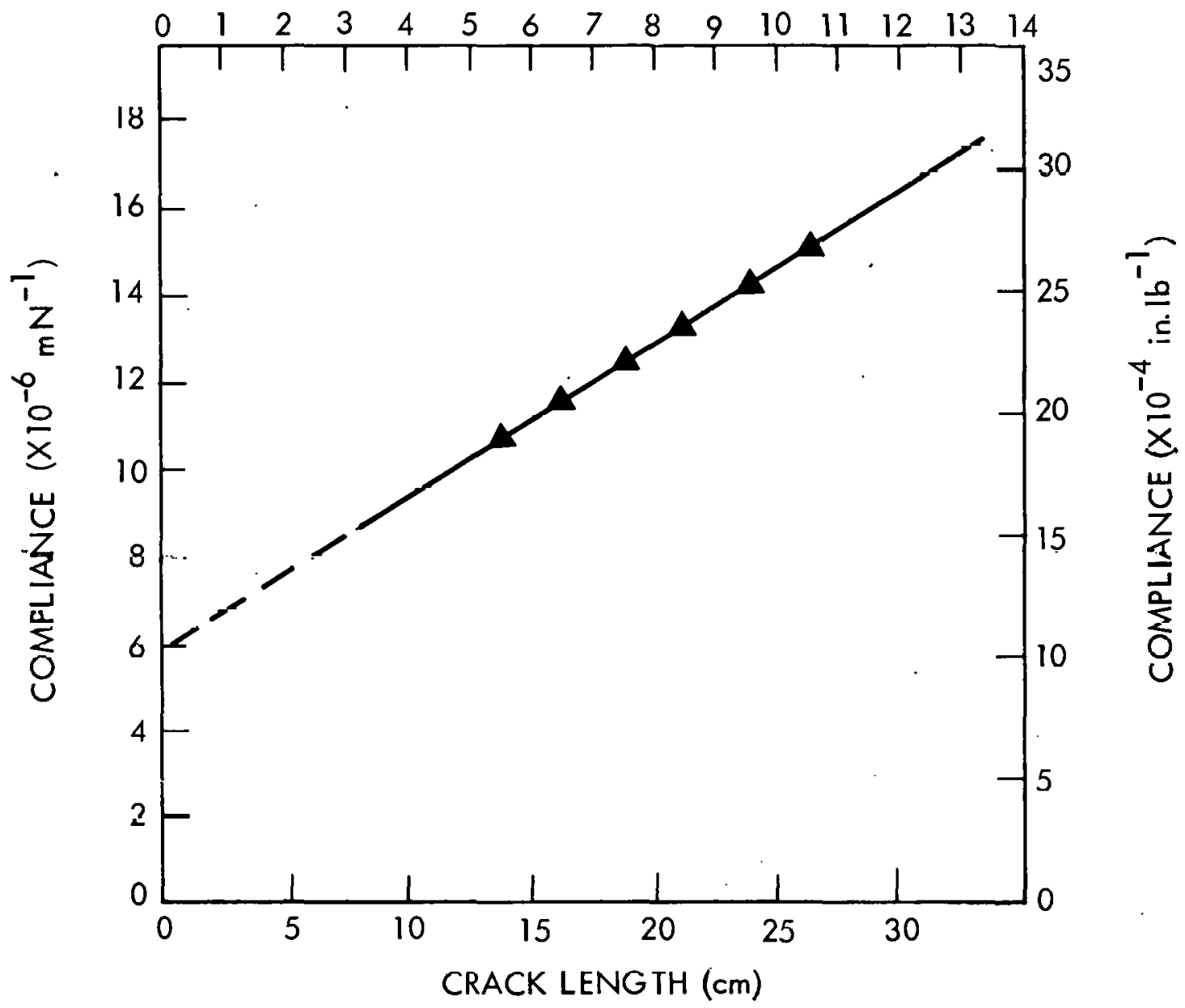

Figure 6. Foamglas ${ }^{\circledR}$ Double Torsion Compliance Calibration 
relaxation tests. From equations (1) and (12) one finds:

$$
\frac{\mathrm{K}_{\mathrm{o}}}{\mathrm{K}_{\mathrm{IC}}}=\frac{\mathrm{P}_{\mathrm{o}}}{\mathrm{P}_{\mathrm{c}}}=\frac{\left(\sigma_{0}\right)_{i}}{(\mathrm{~S})_{i}}
$$

where $\sigma_{o}$ is the distribution of the applied stress below which no slow crack growth will occur and $s$ is the distribution of the inert fast fracture strength, both being functions of the probability of failure of the material, i.e., the flaw severity distribution in the material. Assuming that the flaw distribution which determines $(s)$ is identical to that for $\left(\sigma_{0}\right)$, one may determine the static fatigue limit $\sigma_{0}$ for the cellular glass from the $P_{0}$ and $P_{c}$ values measured from the double torsion tests and from a weakest link statistical analysis of the fast fracture behavior of the material. This distribution of $\left(\sigma_{0}\right)$ would be the lower bound of region I slow crack growth behavior as a function of probability of failure.

Seven thick section specimens $(d=5 \mathrm{~cm}, d w=3.8 \mathrm{~cm}$ ) were loaded to approximately $35 \%-40 \%$ of $\mathrm{K}_{\mathrm{IC}}$ where the crack propagated and $\mathrm{K}_{\mathrm{o}}$ was approached at the low end of the $\mathrm{V}$ vs. $\left(\mathrm{K}_{I} / \mathrm{K}_{I C}\right)$ curve. The specimens were. then rapidly loaded to determine $P_{C}$. The ratio of $\left(K_{o} / K_{I C}\right)$ determined from equation (13) ranged from $25 \%$ to $37 \%$ with an average of $31 \%$. This is in good agreement with the behavior exhibited by dense glass (see References $11-14)$.

A sample population of 49 unnotched specimens of the commercially available Foamglas ${ }^{\circledR}$ soda-lime cellular glass was rapidly fractured in four point loading to determine the fast fracture failure stress distribution $S$. The specimen dimensions and loading configuration were as depicted in Figure 3 with the exception that the sawed notch was not present. Figure 7 is a plot of the two parameter Weibull statistical analysis of the experimental data. Figure 8 is a plot of the probability of failure as a function of $\sigma_{0}$ where from equation (13):

$$
\left(\sigma_{0}\right)_{i}=0.31(\mathrm{~s})_{i}
$$




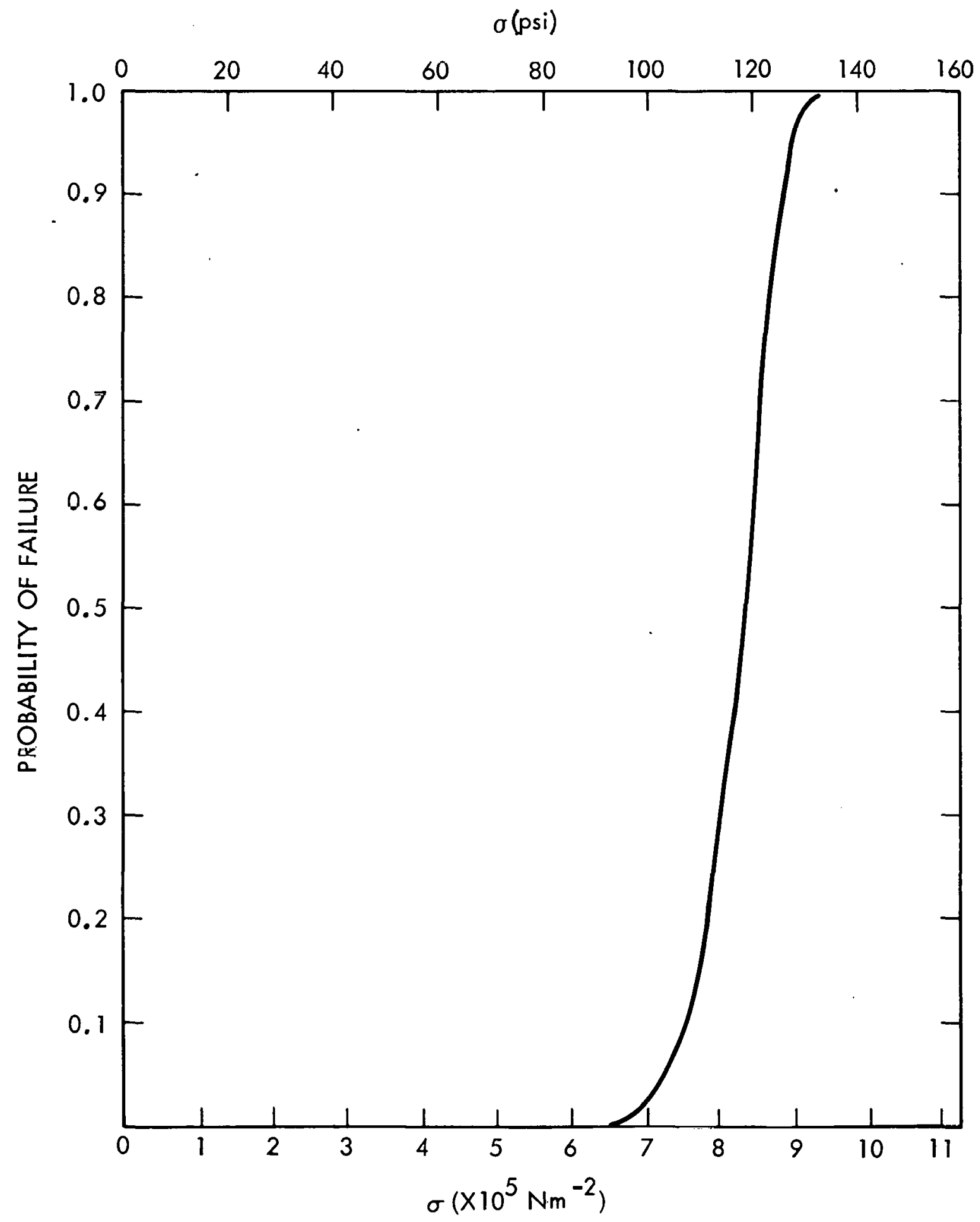

Figure 7. Foamglas ${ }^{\circledR}$ Fast Fracture Strength Weibull Analysis 


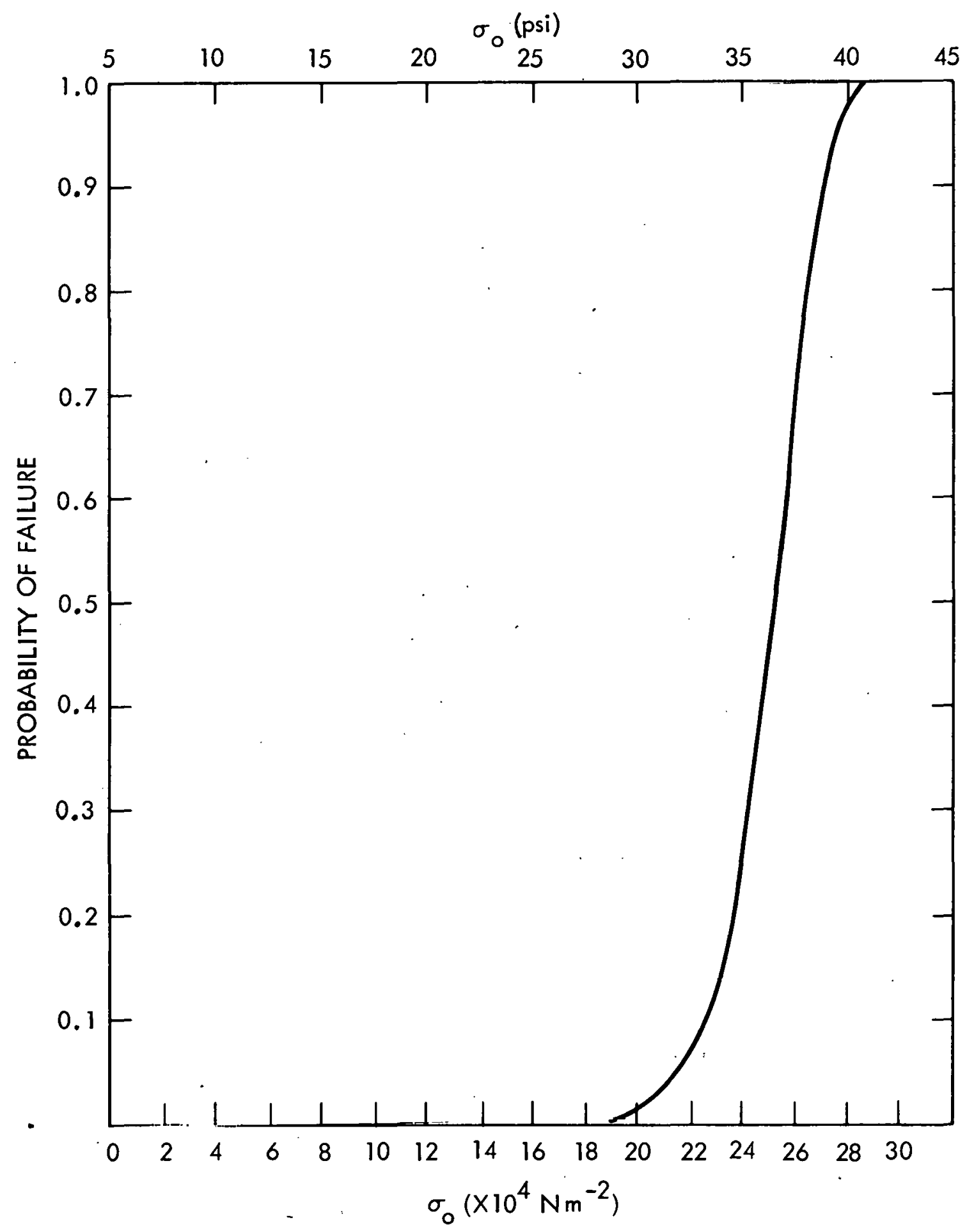

Figure 8. Foamglas ${ }^{\circledR}$ Weibull Probability of Failure vs. the Static Fatigue Stress Limit 
Equations (8) and (12) were employed to analyze the slow crack growth behavior of the Foamglas ${ }^{\circledR}$ soda-lime cellular glass. Data analysis of the thick section specimens yielded invalid results due to the thickness of the specimen. The double torsion analysis assumes a thin plate approaching a membrane. The thick specimens did not conform to this assumption. Thin section $(\dot{d}=1.9 \mathrm{~cm}$, $\mathrm{dw}=1.3 \mathrm{~cm}$ ) specimens with a correction factor for finite thickness of the specimen did result in valid data. Figures 9 and 10 present the slow crack growth behavior of two such thin section specimens. Also included in the figures are curves which are generated from the data of Wiederhorn et a1. (References 18 and 24) for dense soda-lime glass in various humidities, presented on the normalized axis of $\left(\mathrm{K}_{I} / \mathrm{K}_{\mathrm{IC}}\right)$. In this normalization process a value of $7.5 \times 10^{5} \mathrm{Nm}^{-3 / 2}$ was assumed for $K_{I C}$ of dense soda-1ime glass.

The three regions of slow crack growth depicted in Figure 2 are not apparent in the experimental curves of Figures 9 and 10 . This may be a consequence of measuring only over a 1 imited range of $\left(\mathrm{K}_{I} / \mathrm{K}_{\mathrm{IC}}\right)$. The stress corrosion exponents $(n)$, that is, the slopes of the curves shown in Figures 9 and 10 , are plotted in Figure 11 in relation to the percent confidence interval computed from the experimental data. In a similar manner the intercept parameters, $(\beta)$, are plotted in Figure 12. The high values of $n$ measured from these plots indicates a much stronger dependence of the crack velocity on $\left(K_{I} / K_{I C}\right)$, i.e. steeper slope, than has been experimentally observed for dense glass except in Region III. Figure 12 indicates that the slopes of Figures 9 and 10 are indistinguishable above the $87 \%$ confidence intervals. This would indicate that there is some degree of variability in Foamglas ${ }^{\circledR}$ materials which is certainly plausible due to the inhomogeneity of the cellular glass structure.

Diffusion controlled Region II behavior is not observed in Figures 9 and 10. Perhaps this is due to the limited range of $\left(\mathrm{K}_{I} / \mathrm{K}_{\mathrm{C}}\right)$ over which the specimens were tested. However, several investigators (References 25-27) have noted that Region II behavior is a function of the specimen configuration and dimensions. Quackenbush et al (see Reference 27) have demonstrated that Region II behavior is comprised of a combination of environmentally dependent fracture in accessible regions near the sample edges which are accessible by diffusive transport of water vapor, and environmentally independent fracture 


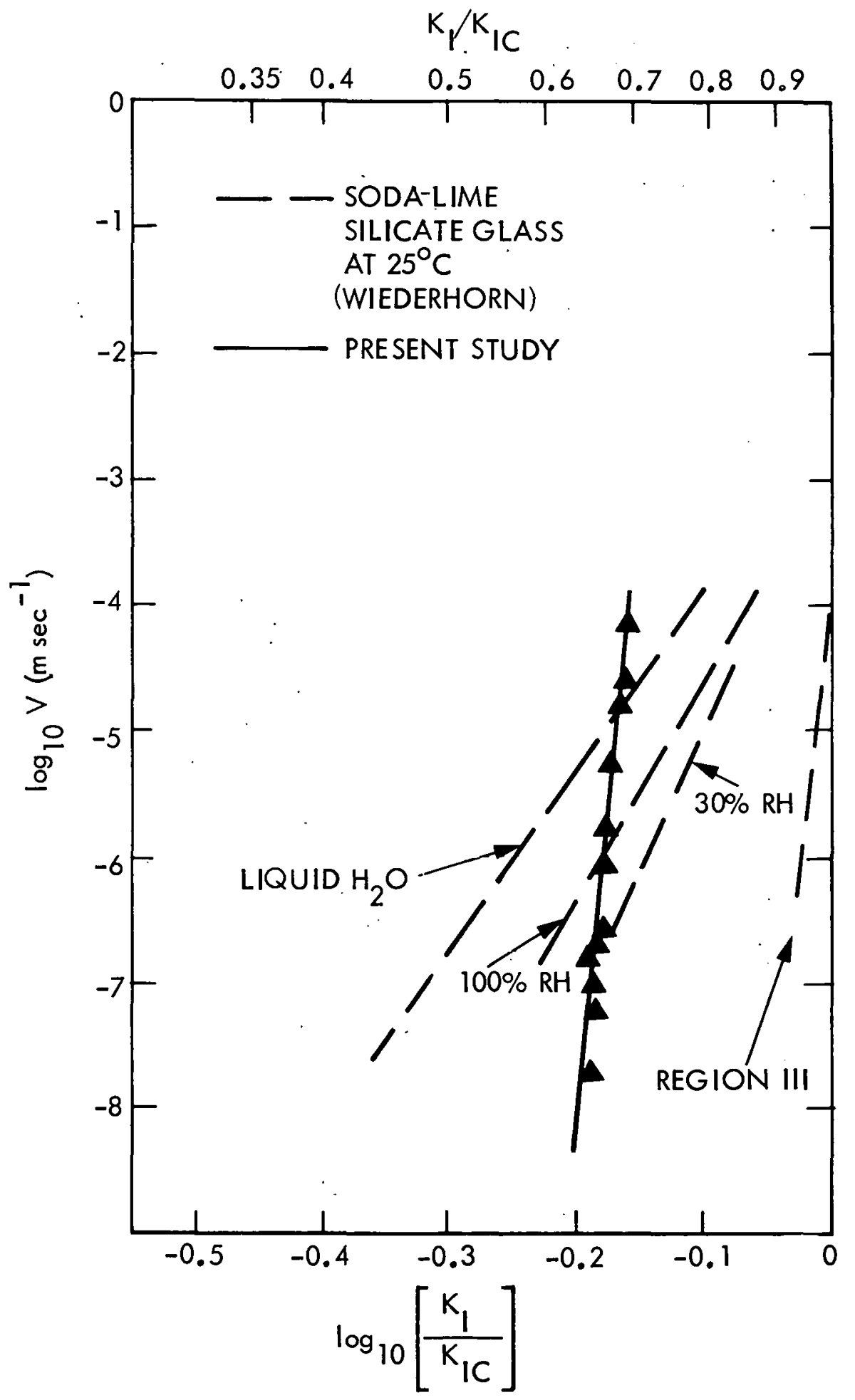

Figure 9. Crack Velocity vs. Stress Intensity Factor for Foamglas ${ }^{\circledR}$ Specimen 1 


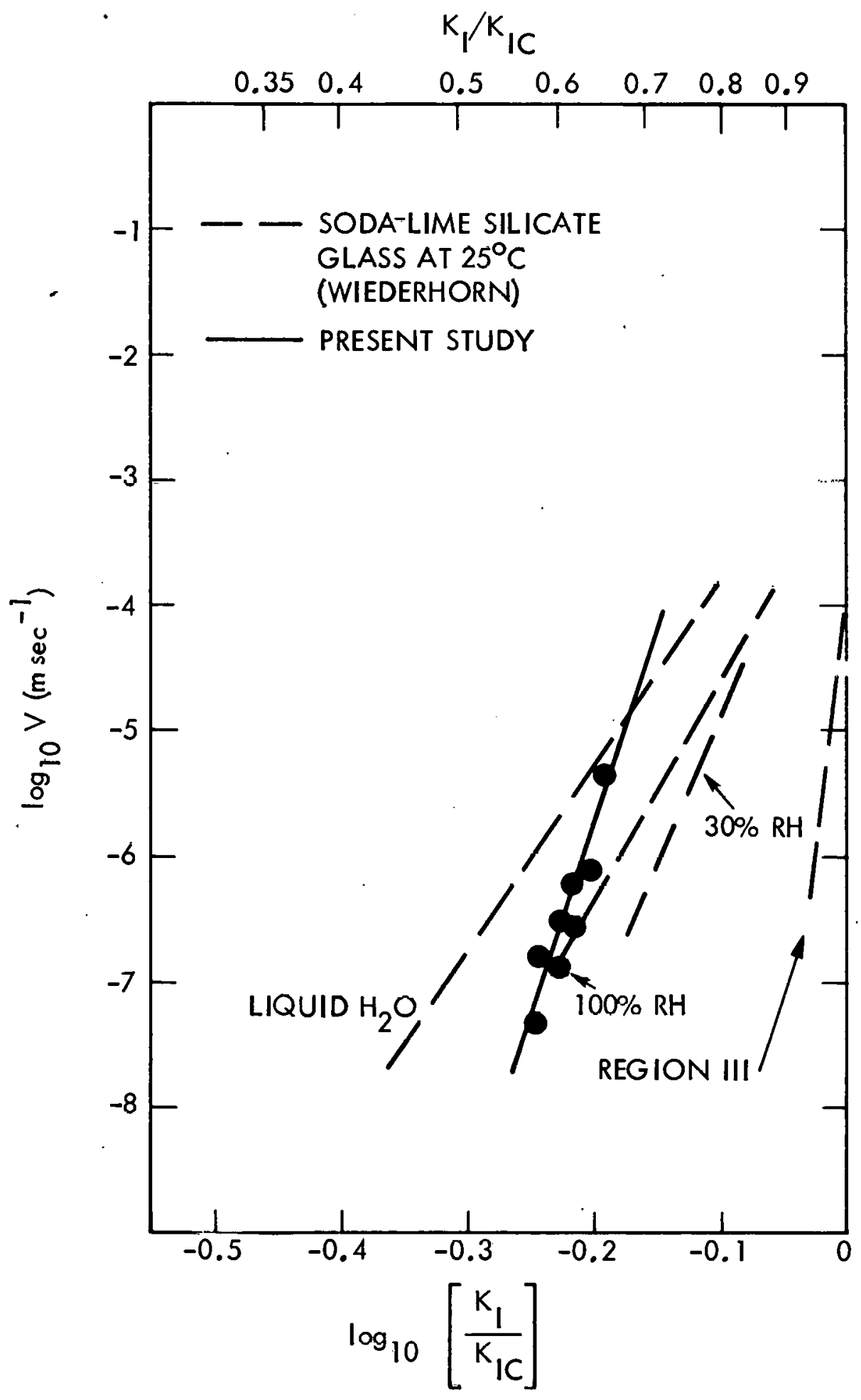

Figure 10. Crack Velocity vs. Stress Intensity Factor for Foamglas ${ }^{\circledR}$ Specimen 2 


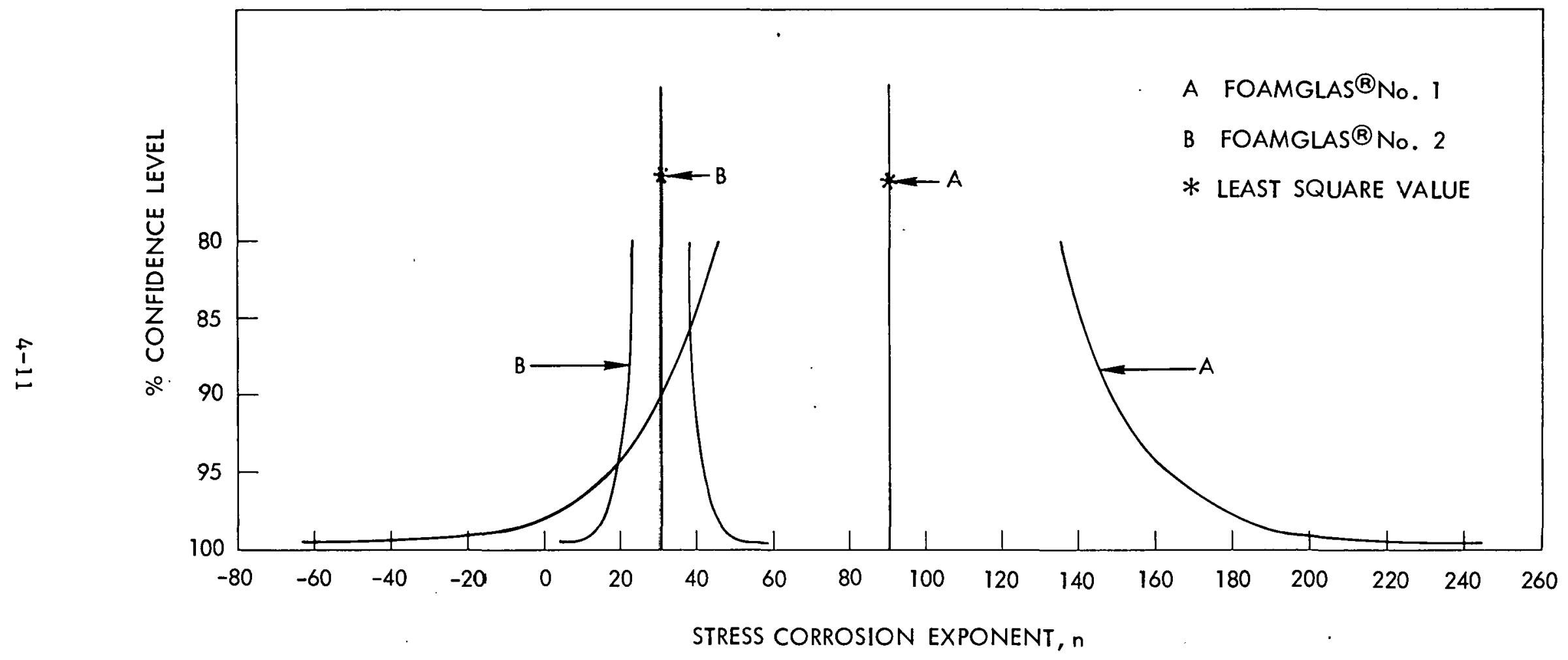

Figure 11. The Stess Corrosion Exponent Intervals Determined From the Curves of Figures $9-10$ for Various Confidence Levels 


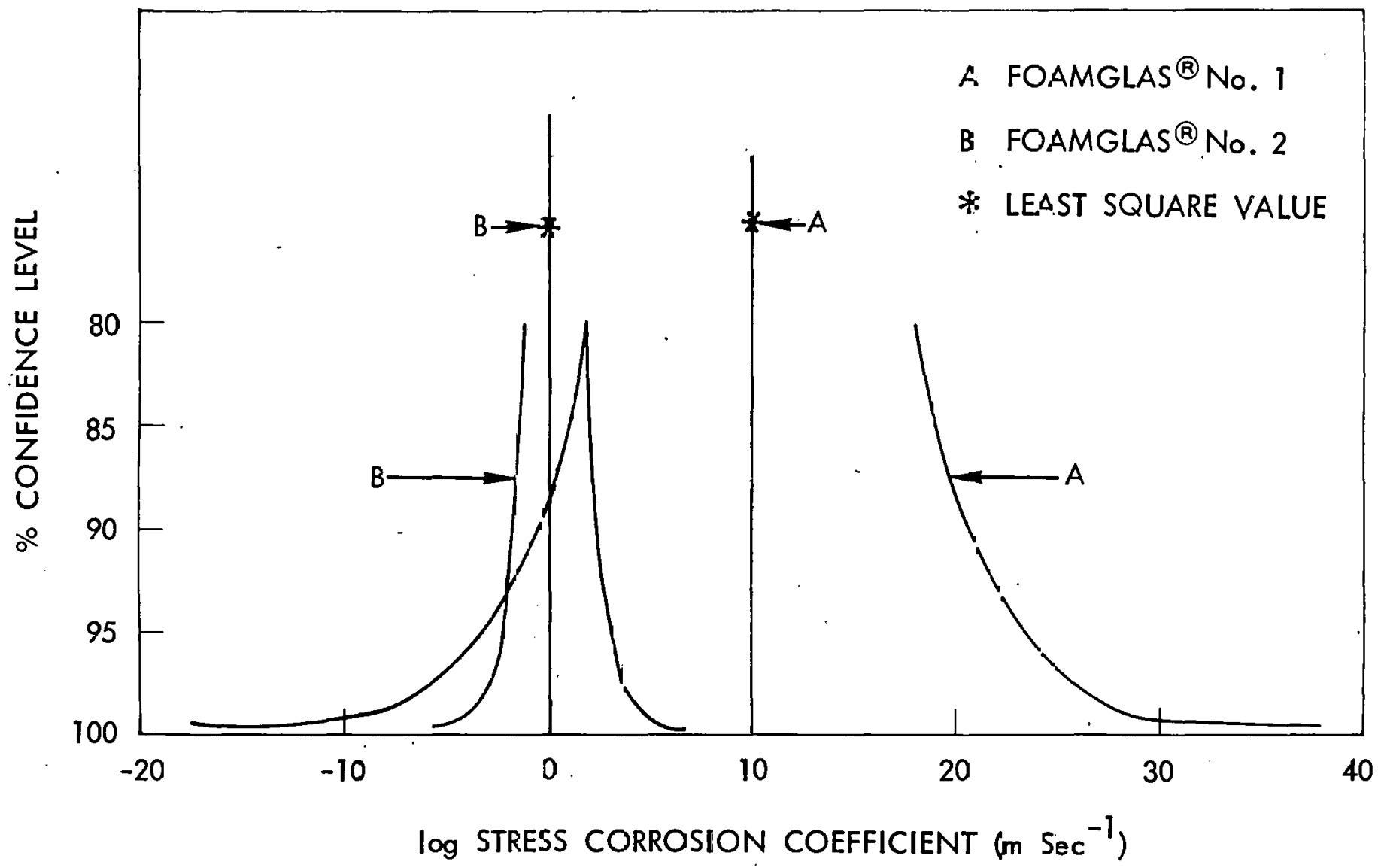

Figure 12. The Stress Corzosion Coefficients Intervals Determined From the Curves of Figures 9-10 for Various Confidence levels 
occurring in the more remote center of the fracture front. Thus, as the specimen thickness decreases, the amount of material in the interior in which the crack is propagating via environmentally independent crack growth also decreases. In the limit of small thickness dimensions, the entire crack front becomes accessible to the corrosive environment and Region I behavior exists up to the point where the combined effects of crack velocity and stress intensification are such that Region III behavior prevails. This process would eliminate Region II behavior altogether. This phenomenon could explain the absence of Region II in cellular glasses. The crack propagates as a through crack in the extremely thin $(<0.1 \mathrm{~mm})$ cell walls. Water vapor in the surrounding pore environment would always be accessible to the crack front, i.e. all diffusion paths from the aqueous cell gas environment to the crack front are short. The diffusion time required is small compared to the residence time of the crack front in the vicinity of the cell, thus environmentally assisted fracture behavior would exist up to velocities sufficient to intersect the Region III curve. Due to the thin cell walls, any appreciable Region II behavior would never occur. The slope of the defined Region I in Figure 10 is approximately 30 . This is greater than the value of 16 usually measured for dense soda-lime glass but in close agreement with the value $31.2+10.3$ measured by Conley et al. (see Reference 3) on the same foamed glass material using the dynamic fatigue technique in flexure tests.

The magnitude of $K_{I}$ at the transition between Region III and Region I crack growth behavior may not be analogous to those seen in dense glasses. This transition may occur at considerably lower velocities than those observed in dense glass because of the reduced flux of water vapor transport to the cells surrounding the advancing crack. In closed cell cellular glasses, water transport from the surface ambient to the crack tip must be through the cells. This is shown schematically in Figure 13.

Effusion of water vapor from the ambient environment through the small cracks in each cell wall is required. In addition, the water vapor may be readily combined with the resident cell gases (e.g., $\mathrm{SO}_{2}$ ) and adsorbed on the activated glass of the cell walls, effectively binding the water chemically and reducing the activity gradient for diffusion. The partial pressure of 


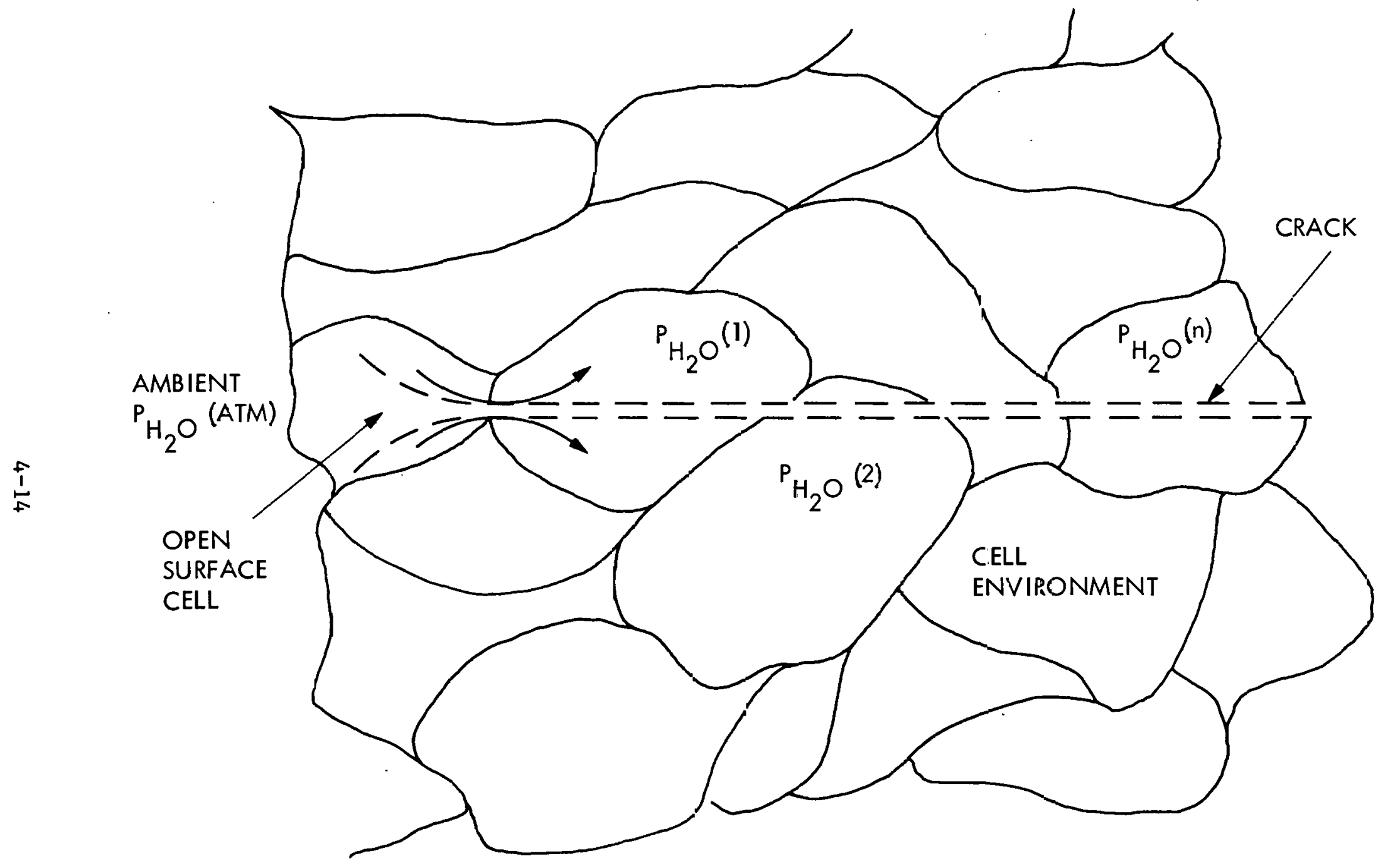

Figure 13. Schematic of hater Transport to the Crack Tip Cellular Glass 
active water vapor in the cell atmosphere would have to be built up in each cell to provide the driving force for diffusion of vapor into the next cell. This reduced rate of water vapor transport may result in a very low partial pressure of water vapor in the cells at the crack tip, even for cracks moving quite slowly. This dry condition at the tips of slowly moving cracks would result in a suppresion of Region I behavior at higher crack velocities where it is normally observed in dense glass (see Figure 14).

The knee in Figure 2 at $k_{0}$ is of interest because it defines the lower boundary for slow crack growth in materials. The data of Weiderhorn et al. (see Reference 24) indicate that the knee for soda-1ime glass in water at $25^{\circ} \mathrm{C}$ occurs at crack velocities of about $10^{-8} \mathrm{~m} \mathrm{sec}^{-1}$. Evans and Weiderhorn (see Reference 10) state that "... o occurs at such low velocities in ceramic materials, $<10^{-10} \mathrm{~m} \mathrm{sec}{ }^{-1}$, that its existence has not been generally proven." If linear behavior is predicted from the range of $\left(\mathrm{K}_{\mathrm{I}} / \mathrm{K}_{\mathrm{IC}}\right)=.31$, determined from the low loading range previously discussed, extrapolation would yield crack velocities at the $k_{0}$ knee in the curve on the order of from $10^{-15} \mathrm{~m} \mathrm{sec}^{-1}$ to $10^{-40} \mathrm{~m} \mathrm{sec}{ }^{-1}$. This has important ramifications for design purposes. If the design lifetime could allow initial crack velocities of $10^{-13} \mathrm{~m} \mathrm{sec}^{-1}$ for flaw growth of $3 \mathrm{~mm}$, the curves would predict design $\left(\mathrm{K}_{\mathrm{I}} / \mathrm{K}_{\mathrm{IC}}\right)$ values of from 0.36 to 0.58 which would greatly increase the allowable design stresses for the material.

The solution for $K_{I C}$ from equation (6a) using the measured $P_{c}$ and $\nu$ calculated from the compliance calibration yields a value of $5.85 \times 10^{4}$ $\mathrm{Nm}^{-3 / 2}$. $\mathrm{K}_{\text {IC }}$ calculated from equation (6a) should be independent of the crack length of the specimen. $K_{\text {IC }}$ calculated from equation (4) using singleedge notched beam data is strongly dependent upon crack length. The crack length used in equation (4) was the measured depth of the sawed notch. The machining process, by its very nature, introduces microflaws into the material thereby extending the length of the notch beyond the measured depth. The lengths of these extensions are unknown (possibly related to the cell size of the cellular glass) but one would expect $\mathrm{K}_{\mathrm{IC}}$ values measured in notched beams to be somewhat less than values measured in the crack length independent double torsion test. 


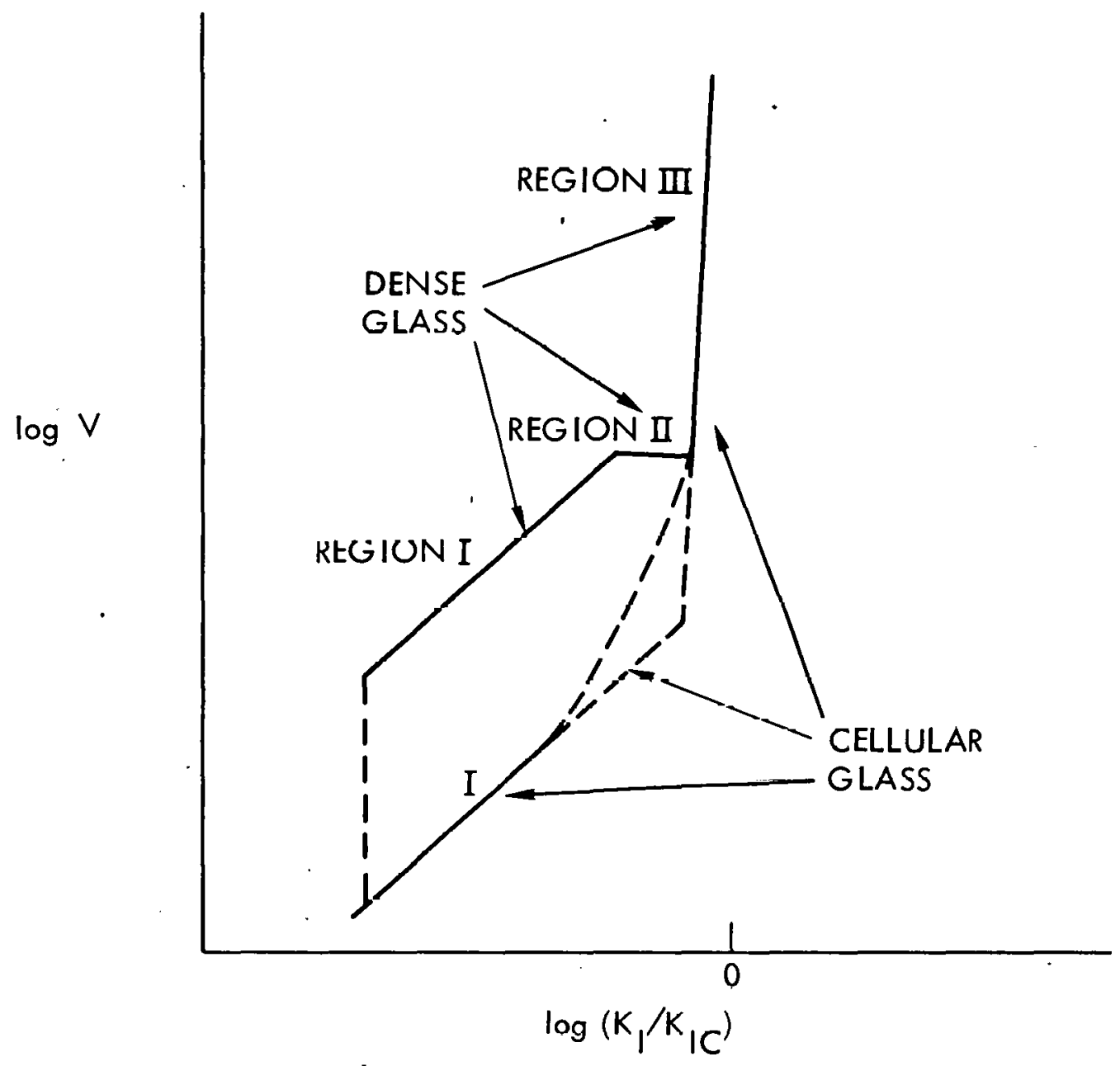

Figure 14. A Comparison of the Slow Crack Growth Behavior for Cellular Glasses in Relation to that of Dense Glasses 
In any given number of $\mathrm{SENB}$ specimens it is reasonable to expect that the lengths of the microflaws produced ahead of the sawed notch by the machining process would be distributed over some range. In a very large number of specimens this size range of small flaws ahead of the sawed notch would extend from zero to some maximum value. If $K_{I C}$ is assumed to be a material constant, Equation 4 indicates that the effect of increasing the crack length would be a decrease in the critical applied load. Since the experimental data analysis utilizes the measured critical load and the measured value for the sawed notch depth to determine $K_{I C}$ from equation 4 , the effect. of an unknown increase in crack length due to machining microflaws would lead to a low estimate of the $\mathrm{K}_{\mathrm{IC}}$ for the material. It is not important to determine this flaw size distribution but to realize that the notch depth measured on the specimen with the smallest microflaw ahead of it would be the closest approximation to the actual notch depth of any specimen in that sample population. Testing of this specimen would result in the largest calculated value of $\mathrm{K}_{\mathrm{IC}}$ and would therefore be the best approximation of the $\mathrm{K}_{\mathrm{IC}}$ of the sample population.

The maximum of $\mathrm{K}_{\text {IC }}$ measured on 29 Foamglas ${ }^{\circledR}$ SENB specimens was $5.57 \mathrm{x}$ $10^{4} \mathrm{Nm}^{-3 / 2}$ which is within $5 \%$ the value $5.85 \times 10^{4} \mathrm{Nm}^{-3 / 2}$ measured from the double torsion specimen. The maximum values measured on the two developmental cellular glasses are $7.00 \times 10^{4} \mathrm{Nm}^{-3 / 2}$ and $1.20 \times 10^{5} \mathrm{Nm}^{-3 / 2}$. The maximum values of $\dot{K}_{I C}$ measured from the three sample populations as a function of density are included on the plot of Figure 5. Extrapolation of the least squares fitted linear curve through these three points to the density value for dense glass yields a value of $\mathrm{K}_{\mathrm{IC}}=0.77 \mathrm{MNm}^{-3 / 2}$ which is in close agreement with accepted values of this quantity (see insert Figure 5). These maximum values of $\mathrm{K}_{\mathrm{IC}}$, for cellular glasses, tend to lie at the high end of the density distribution for each sample population. Insufficient data existed to adequately consider the confounding effect of density variation within each population in this simplified extrapulaliun. An analysis which considers this density variation is expected to yield results similar to those presented here. 
C. CRItICAL STRAIN ENERGy RELEASE RATE, $G_{\text {IC }}$

$G_{\text {IC }}$ values were calculated from equation (5) using the maximum values of $\mathrm{K}_{\mathrm{IC}}$ measured from each notched beam sample population as the best estimate for $\mathrm{K}_{\mathrm{IC}} \cdot$ Young's modulus values were determined from independent measurements of four point loaded unnotched beams. The calculated values of $G_{I C}$ ranged from 2.2 to $4.8 \mathrm{Jm}^{-2}$. Wiederhorn (Reference 23) reports values ranging from 7.6 to $9.5 \mathrm{Jm}^{-2}$ for dense glasses. The difference in these values is unexplainable at present.

D. CRITICAL FLAW SIZE DISTRIBUTION, $\mathrm{C}_{\mathrm{c}}$

The distribution of the inherent critical flaw size distribution for a sample population of cellular glass can be derived from equation (1) and a Weibull weakest link statistical analysis for the probability of failure as a function of fast fracture applied stress. This distribution is given by the following relation:

$$
C_{c}=\left(\frac{K_{I C}}{Y \theta}\right)^{2} \quad\left\{\log \left(\frac{1}{I-P}\right)\right\}^{-2 / m}
$$

where $C_{c}$ is the critical flaw size distribution, $m$ is the Weibull slope, $\theta$ is the scale parameter in the Weibull analysis, $P$ is the probability of failure and the other parameters are defined in equation (1). Three cases for Foamglas ${ }^{\circledR}$ specimens are analyzed, two on a macroscale and one on a microscale.

Case 1 , on the macroscale, assumes the bulk value estimate for $\mathrm{K}_{\mathrm{IC}}=$ $5.6 \times 10^{4} \mathrm{Nm}^{-3 / 2}(50.7 \mathrm{psi}$ in $1 / 2), \mathrm{m}=19.79$ and $\theta=8.31 \times 10^{5} \mathrm{Nm}^{-\frac{1}{2}}$ $(120.42 \mathrm{psi})$ determined from the two parameter Weibull analysis of Foamglas ${ }^{\circledR}$ fast fracture tests, and $Y=1.128$ for a penny-shaped crack (Reference 28). The resulting equation becomes:

$$
c_{c}=0.353\left\{\log \left(\frac{1}{1-P}\right)\right\}^{-0.10} \mathrm{~cm}
$$


This case would be applicable to a half-penny-shaped flaw on the surface of the cellular glass specimen. This distribution of critical flaw size is illustrated in curve 1 of Figure 15.

Case 2 is also on a macroscale and assumes the same bulk values for the various parameters with the exception of the geometric parameter $Y$. In this case $Y=1.985$ corresponding to an edge notch into a semi-infinite plate subjected to tension (see Reference 2). The equation for the flaw size distribution in this case becomes:

$$
c_{c}=0.114\left\{\log \left(\frac{1}{1-P}\right)\right\}^{-0.10} \mathrm{~cm}
$$

- This case approximates a flaw on the tensile surface traversing the width of the specimen. It is conceivable that a flaw composed of connected open surface pores may traverse the surface of the specimen. This flaw size distribution is illustrated in curve 2 of Figure 15.

Case 3 treats the model, on a microscale, as a through surface crack in the thin wall of an individual cell. It assumes $\mathrm{k}_{\mathrm{IC}}=7.5 \times 10^{5} \mathrm{Nm}^{-3 / 2}$ (682.4 psi in. ${ }^{1 / 2}$ ) for dense glass, $m=19.79$ determined from the Weibull analysis and a value for $\theta$ adjusted to account for the stress in the cell wall. A value for the stress in the cell wall is derived in Appendix A as being 27.8 times the bulk stress value. Therefore $\theta$ is estimated to be $2.31 \times 10^{7} \mathrm{Nm}^{-2}$ ( $3350 \mathrm{psi}$ ). The equation for this flaw size distribution becomes:

$$
c_{c}=0.028\left\{\left.\log \left(\frac{1}{1-P}\right)\right|^{-0.10} \mathrm{~cm}\right.
$$

This distribution is illustrated in curve 3 of Figure 15.

The three cases present models that are plausible. No attempt to verify or disprove any model has been attempted in this study. The small magnitude 


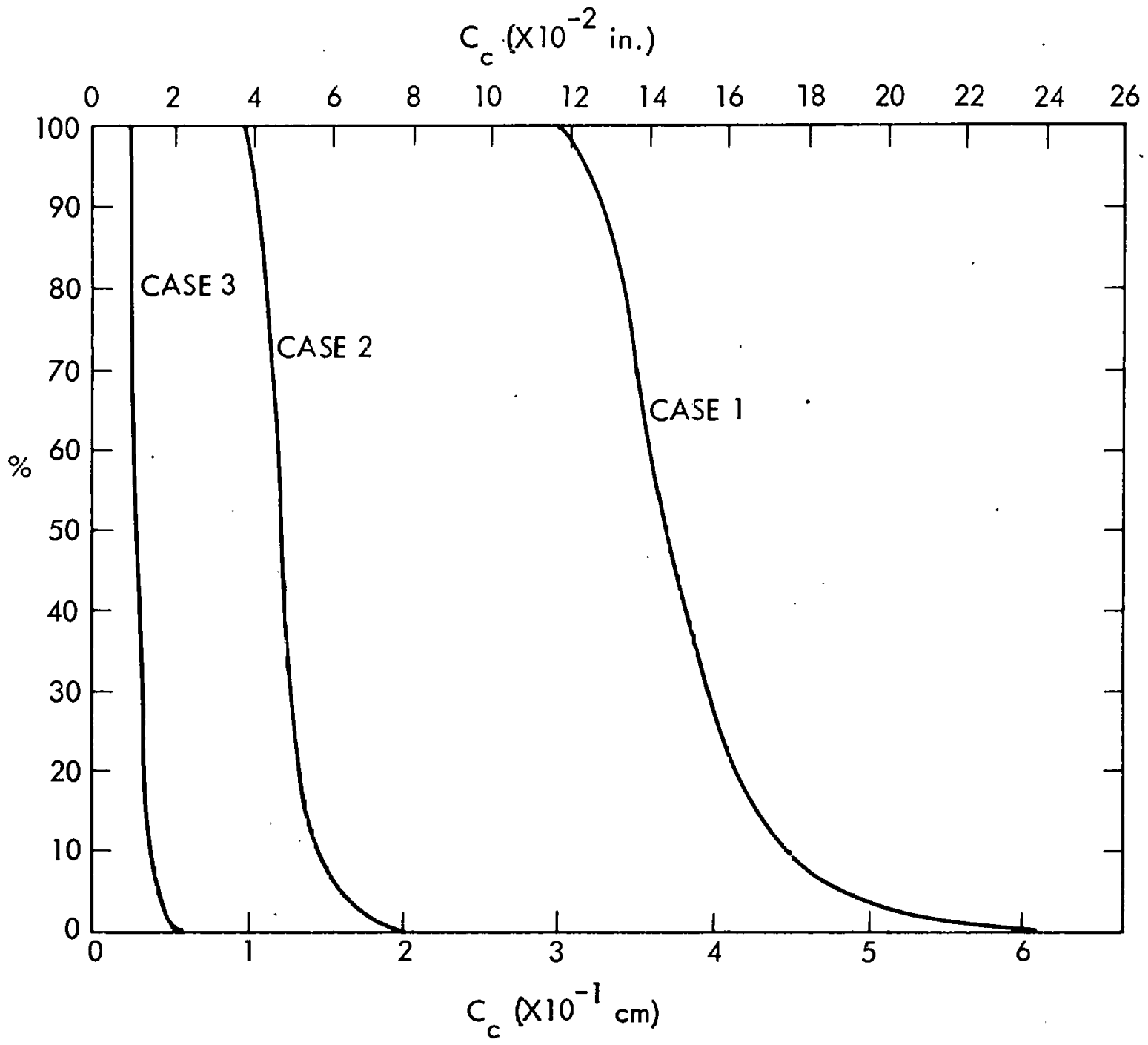

Figure 15. The Critical Flaw Size Distribution in Foamglas ${ }^{\circledR}$ fcr Various Flaw Models: Case 1 , a Penny-shaped Flaw on the Surface of the Surface of the Specimen; Case 2, a Through Notch Across the Specimen Surface; Case 3, a Through Crack in Cell Glass Wall 
of the flaw size predicted by case 3, however, is subject to question. The machining process of sample preparation is expected to introduce flaws of this magnitude or greater. If the stress in the cell walls is actually higher than predicted by the model described in Appendix A due to "structural" effects in the microstructure, the flaw size distribution would be shifted to smaller sizes.

The case 2 prediction is of a believable magnitude, on the order of the pore size. Conceivably the open pores could be connected across the thickness of the specimen and would lead to a through crack across the surface. Case 3 predicts rather large penny-shaped flaws which have not been verified. 
SECTION $V$

SUMMARY

The bulk critical stress intensity factors of one commercial and two developmental cellular glasses were measured using single-edge notched beams in four points bending. A linear dependence of fracture toughness on density has been determined over the range of low densities investigated. Extrapolation of the linear curve to densities of dense glass shows good agreement with 1 iterature values for $\mathrm{K}_{\mathrm{IC}}$ of dense glasses.

$K_{0}, V$ vs. $K_{I}$ and $K_{I C}$ determinations were made on the commercially available cellular glass utilizing the double torsion technique. $\mathrm{K}_{\mathrm{o}} / \mathrm{K}_{\mathrm{IC}}$ values ranging from 0.25 to 0.37 were observed to be in good agreement with observations on dense glass. The $V$ vs. $K_{I}$ relationship exhibited a much steeper dependence of the slope of $V$ upon $K_{I}$ than has usually been observed for dense glass. Region II diffusion controlled slow crack growth behavior was conspicuously absent indicating water vapor from the pore environment may always be available at the tip of the growing crack. A physical model has been presented explaining this. The compliance calibration of the double torsion specimen provided a determination of Poisson's ration $\nu=0.17$ and $\mathrm{K}_{\mathrm{IC}}$ was determined to be $5.85 \times 10^{4} \mathrm{Nm}^{-3 / 2}$.

Microflaws are believed to be introduced by the machining process at the base of the notch in the SENB specimens used in this study. These microflaws result in the actual crack length being larger than the measured one by an unknown amount. This results in an incorrect, lower calculated value for $\mathrm{K}_{\mathrm{IC}}$. The maximum calculated value for $K_{I C}$ is believed to be obtained with the specimen which contains the mimimum size microflaw ahead of the machined notch and is therefore the best estimate for the $K_{I C}$ of the sample population.

The critical flaw size distribution has been analyzed for three models of the flaws in Foamglas ${ }^{\circledR}$. Microstructural analyses have not been undertaken to verify which of the three cases is the active system. The model consisting of open surface pores linked across the width of the specimen appears to be more plausible explanation. 


\section{SECTION VI}

\section{CONCLUSIONS}

This report details the findings of one part of a program to develop and characterize the behavior of cellular glasses to determine their suitability for utilization as a structural material in solar optical structures. Based upon the results of this study alone, a recommendation as to the durability or reliability of cellular glasses in optical structures cannot be made. Such a recommendation must be made based upon the results of the entire program. The intent of the investigation reported herein was to make certain fundamental laboratory measurements on the materials. Because of time and funding limitations, these measurements were accomplished on only a small sample of materials. No attempt was undertaken to evaluate the statistical variation of materials from different production runs. A follow-up study would be required to evaluate properties over months of production, to provide representative engineering design data on production materials. It is felt that the basic behavior and mechanisms determined in the present study should describe generally the behavior of any lot or batch of this material.

The following may be concluded from the results of this study:

- Slow crack growth behavior appears to be a more complex phenomenon in cellular glasses than in dense glass.

- lhe existence of the strèss corrosion thréshold, $k_{0}$, was not conclusively established for cellular glass.

- Crack velocity at any $\mathrm{K}_{\mathrm{I}}$ level may be dependent upon water vapor transport to the crack tip, more so than in dense glass or ceramics.

- V vs. $\mathrm{K}_{\mathrm{I}}$ crack growth behavior is dependent upon the crack lengths in the material due to the fact that water vapor transport is dependent upon crack length. It has not been necessary to consider this in dense glass and ceramics.

$$
6-1
$$


The data measured in this study provide a description of slow crack growth behavior in one regime of time, crack length, stress and resulting velocities. However, the behavior observed in this short study may not be representative of the behavior of a cellular glass component in the field during a thirty year service life. To predict real service lifetimes with high confidence, additional work will be required. Two options for increasing the confidence of prediction are available. The first is long term static fatigue testing. The second, requires a matrix of accelerated tests to determine the time dependence of water vapor diffusion to the crack tip. This testing would provide an understanding of the complex phenomena involved in the slow crack growth process which is necessary for predicting long term behavior.

The identification of a stress corrosion threshold, $\mathrm{K}_{\mathrm{O}}$, was made difficult by the fact that the material did not exhibit the typical stress corrosion behavior described as regions I, II and III. From the results of the present work, it appears that water assisted slow crack growth will be slower in the cellular glasses than in dense glass. If extrapolations to low crack growth velocities from the present data can be justified, design stresses on the order of $35 \%$ of the fast fracture stress ( $\mathrm{S}$ ), corresponding to initial crack velocities on the order of $10^{-13} \mathrm{~m} \mathrm{sec}-1$, may be possible. It should be recognized, however, that the parameter $(\sigma / S)=\left(\mathrm{K}_{\mathrm{I}} / \mathrm{K}_{\mathrm{IC}}\right)$ is not sufficient to determine the time required for a crack to reach a critical size. The time required for a crack to grow from initial to critical size is also dependent upon the initial crack length. Both the $\mathrm{V} v \mathrm{~s} .\left(\mathrm{K}_{\mathrm{I}} / \mathrm{K}_{\mathrm{IC}}\right)$ relationship and the initial flaw size distributions are required to predict lifetimes. 
REFERENCES

1. Giovan, M., and M. Adams, Evaluation of Cellular Glasses for Solar Mirror Panel Applications, JPL Publication 79-61. June 15, 1979.

2. Paris, P.C., and G.C. Sih, ASTM Special Technical Publ. No. $381 ; 1965$.

3. Conley, P.H., Chandan, H.C., and Bradt, R.C., "Dynamic Fatigue of Foamed Glass," Fracture Mechanics of Ceramics, Vol. IV, Edited by Bradt et al., Plenum Press, New York, 1978.

4. Charles, R.J., "Static Fatigue of Glass: I, II," J. App1. Phys. Vo1. 29 No. 11 , pp. 1549-1560, 1958.

5. Wiederhorn, S.M., "A Chemical Interpretation of Static Fatigue," J. Am. Ceram. Soc., Vol. 55, No. 2, pp. 81-85, 1972.

6. Mịnnear, W.P., and Bradt, R.C., "(K-V) Diagrams for Ceramic Materials," ibid., Vol. 58, No. 7-8, pp..345-46, 1975.

7. Sines, G., "Rationalized Crack Growth and Time-to-Fracture of Brittle Materials," ibid., Vol. 59, No. 7-8, pp. 370-71, 1976.

8. Wiederhorn, S.M., "Influence of Water Vapor on Crack Propagation in Soda-Lime Glass," ibid., Vol. 50, No. 8, pp. 407-414, 1967.

9. Evans, A.G., "A Method for Evaluating the Time-Dependent Failure Characteristics of Brittle Materials - and its Application to Polycrystalline Alumina," J. Mat. Sci., No. 7, pp. 1137-1146, 1972.

10. Evans, A.G. and Wiederhorn, S.M., "Proof Testing of Ceramic Materials An Analytical Basis for Failure Prediction," Int. J. Fracture, Vol. 10, No. 3, pp. 379-392, 1974. 
11. Holland, A.J., and Turner, W.E.S., "The Effect of Sustained Loading on the Breaking Strength of Sheet Glass," J. Soc. Glass Tech., Vol. 24, No. 101 , pp. 46-57, 1940 .

12. Baker, T.C., and Preston, F.W., "Fatigue of Glass under Static Loads," J. Appl. Phys., Vol. 17, pp. 170-178, 1946.

13. Shand, E.B., "Experimental Study of Fracture of Glass: I, The Fracture Process," J. Amer. Ceram. Soc., Vo1. 37, No. 2, pp. 52-60, 1954.

14. Mould, R.E., "Strength and Static Fatigue of Abraded Glass Under Controlled Ambient Conditions: IV, Effect of Surrounding Medium," J. Amer. Ceram. Soc., Vol. 44, Nọ. 10, pp. 481-491, 1966.

15. Brown Jr., W.F., and Strawley, J.E., Plane Strain Crack Toughness Testing of High Strength Metallic Materials, ASTM Special Technical Publication No. 410, ASTM Philadelphia, Pennsylvania, 1966.

16. Williams, D.P., and Evans, A.G., "A Simple Method for Studying Slow Crack Growth," Journal of Testing and Evaluation, Vol. I, No. 4, pp. 264-270, July 1973.

17. Evans, A.G., "A Simple Method for Evaluating Slow Crack Growth in Brittle Materials," Int. J. Fracture, Vol. 9, No. 3, pg. 267, 1973.

18. Weiderhorn, S.M., "Subcritical Crack Growth in Ceramics," Eracture Mechanics of Ceramics, Vol. II, edited by Bradt et al., Plenum Press, New York, 1974.

19. Beachem, C.D., Kies, J.A., and Brown, B.F., "A Constant K Specimen for Stress Corrosion Cracking Tests," Materials Research and Standards, MTRSA, Vol. II, No. 4, pg. 30, 1969.

20. Fuller E.R., Jr., "An Evaluation of Double Torsion Testing-Analysis," ASTM Special Technical Publication 678, "Fracture Mechanics Applied to Brittle Materials," pp. 3-18, 1979. 
21. Pletka, B.J., Fuller, E.R., Jr., and Koepke, B.G., "An Evaluation of Double Torsion Testing-Experimental," ibid., pp. 19-37, 1979.

22. Shetty, D.K., and Virkar, A.V., "Determination of the Useful Range of Crack Lengths in Double Torsion Specimens," J. Am. Ceram. Soc., Vol. 61, No. 1-2, pg. 93, 1978.

23. Wiederhorn, S.M., "Fracture Surface Energy of Glass," J. Am. Ceram. Soc., Vol. 52, No. 2, pp. 99-105, 1969.

24. Wiederhorn, S.M., and Bolz, L.H., "Stress Corrosion and Static Fatigue of Glass," J. Amer. Cer. Soc., Vol. 53, No. 10, pp. 543-548, 1970.

25. McKinney, K.R., "Effect of Specimen Size on Crack Propagation in Glass," Rep. NRL. Prog. No. 9, pp. 27-29, 1974.

26. Chandan, H.C., Bradt, R.C., and Rindone, G.E., "Dynamic Fatigue of Float Glass," J. Am. Ceram. Soc., V̇ol. 61, No. 5-6, pp. 207-210, 1978.

27. Quackenbush, C.L., and Frechette, V.D., "Crack-Front Curvature and Glass Slow Fracture," ibid., Vol. 61, No. 9-10, pp. 402-406, 1978.

28. Sneddon, I.N., "The Distribution of Stress in the Neighborhood of a Crack in an Elastic Solid," Proc. Roy. Soc., London A187, Pg. 229, 1946. 
A MODEL FOR THE MECHANICAL BEHAVIOR OF FOAMGLAS ${ }^{\circledR}$

\section{A.1 Definitions}

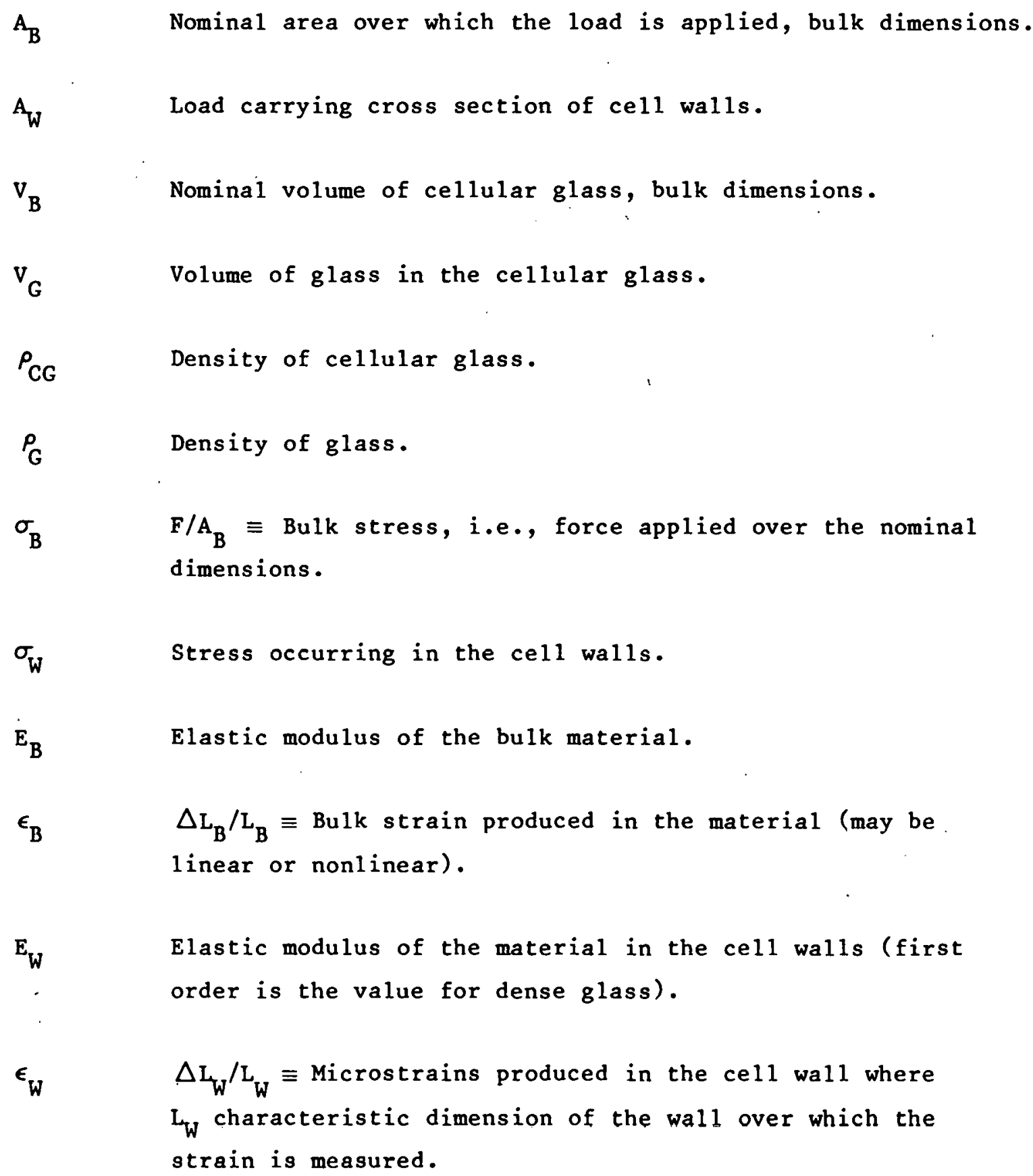




\section{A.2 Cellular Glass Mode1}

For the bulk cellular glass material:

$$
\sigma_{B}=E_{B} \epsilon_{B}
$$

For the material in the cell walls:

$$
\sigma_{W}=E_{W} \epsilon_{W}
$$

If under load all the bulk strain is the result of extensional displacement in the wall material i.e., no flexing or bending of the cell walls

$$
\epsilon_{B}=\epsilon_{W}
$$

and

$$
\sigma_{\mathrm{B}} / \underline{E}_{\mathrm{B}}=\dot{\sigma}_{\mathrm{W}} / \mathrm{E}_{\mathrm{W}}
$$

Rearrangement leads to the following:

$$
\sigma_{B} / \sigma_{W}=E_{B} / E_{W}=\left(F_{B} / A_{B}\right) /\left(F_{W} / A_{W}\right)
$$

Noting that $F_{B}=F_{W}$ lead to:

$$
\left(\sigma_{B} / \sigma_{W}\right)=\left(E_{B} / E_{W}\right)=\left(A_{W} / A_{B}\right)
$$




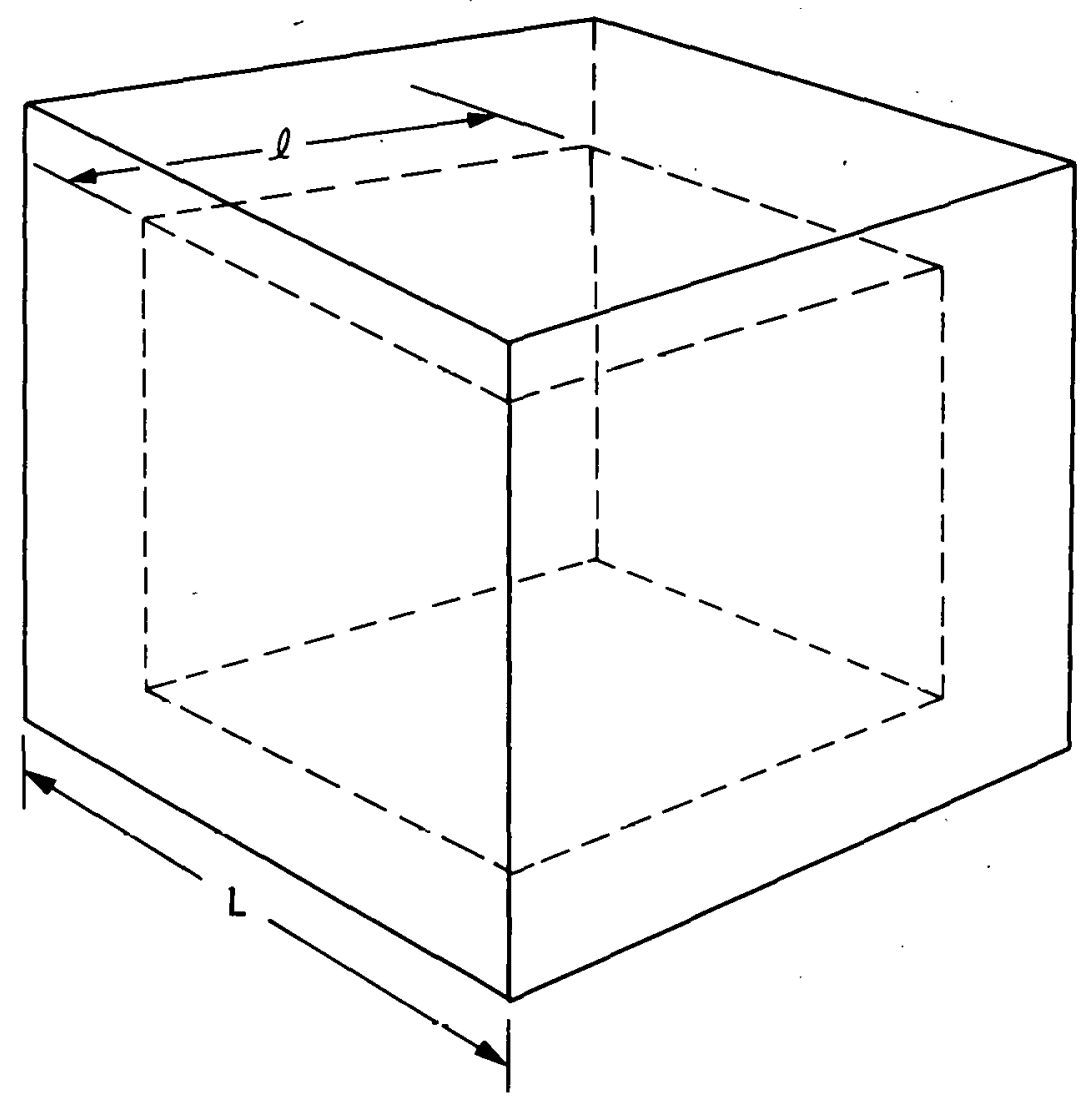

Figure A-1. The "Egg-Crate" Model for Cellular Glass 
Assuming an "egg crate" model, depicted in Figure A-1 for cellular glass, the fraction of glass in the nominal volume of the cellular glass is the following:

$$
\frac{V_{W}}{V_{B}}=\frac{L^{3}-l^{3}}{L^{3}}
$$

where $L$ and $l$ are defined in Figure $A 1$. The fraction of load carrying glass area in the nominal area of the cellular glass is given by:

$$
A_{W} / A_{B}=\frac{L^{2}-l^{2}}{L^{2}}
$$

For a unit length cell $(L=1)$ Equation A7 becomes:

$$
1-\ell^{3}=\mathrm{v}_{\mathrm{W}} / \mathrm{v}_{\mathrm{B}}=\frac{P_{\mathrm{CG}}}{P_{\mathrm{G}}}
$$

Solving for $\ell$ yields:

$$
\ell=\left(1-\frac{P_{\mathrm{CG}}}{\rho_{\mathrm{G}}}\right)^{1 / 3}
$$

Substituting Equation Al0 into Equation A8 yields:

$$
\mathrm{A}_{\mathrm{W}} / \mathrm{A}_{\mathrm{B}}=1-\ell^{2}=1-\left(1-\frac{P_{\mathrm{CG}}}{\rho_{\mathrm{G}}}\right)^{2 / 3}
$$


Combining Equations $A 6$ and All yields:

$$
\mathrm{E}_{\mathrm{B}} / \mathrm{E} \underset{\mathrm{W}}{\mathrm{A}} \mathrm{A}_{\mathrm{A}}=1-\left(1-\frac{P_{\mathrm{CG}}}{P_{\mathrm{G}}}\right)^{2 / 3} .
$$

From Equation A6 one finds:

$$
\frac{\sigma_{W}}{\sigma_{B}}=\frac{E_{W}}{E_{B}}=\frac{1}{1-\left(1-\frac{\rho_{C G}}{\rho_{G}}\right)^{2 / 3}}
$$

Substituting in values of $0.14 \mathrm{gm} \mathrm{cm}^{-3}(8.5 \mathrm{pcf})$ for the density of Foamglas ${ }^{\circledR}$ and $2.55 \mathrm{gm} \mathrm{cm}^{-3}$ (159.2 pcf) for the density of dense glass yields the stress of the cell wall to be 27.84 times the measured bulk stress for this simplified model. 